\title{
New Tools for Molecular Imaging of Redox Metabolism: Development of a Fluorogenic probe for 3马-Hydroxysteroid Dehydrogenases
}

\author{
Dominic J. Yee, Vojtech Balsanek, Dalibor Sames* \\ Department of Chemistry, Columbia University, New York NY 10027 \\ sames@chem.columbia.edu
}

Supporting Information

\section{Materials and General methods}

${ }^{1} \mathrm{H}$ and ${ }^{13} \mathrm{C}$ NMR spectra were recorded on Bruker 300 or 400 Fourier transform NMR spectrometers. Spectra were recorded in $\mathrm{CDCl}_{3}$ solutions referenced to TMS or the solvent residual peak unless otherwise indicated. IR spectra were taken as neat for liquids on $\mathrm{NaCl}$ plates or as $\mathrm{KBr}$ pellets for solids using a Perkin-Elmer 1600 FTIR spectrometer. High Resolution Mass Spectra were obtained on a JOEL JMS-HX110 HF mass spectrometer. Flash chromatography was performed on SILICYCLE silica gel (230400 mesh). All chemicals were purchased from Aldrich and used as received. All reactions were monitored by Thin Layer Chromatography.

Ultraviolet spectra were measured on a Cary $100 \mathrm{UV}$-Visible spectrophotometer and recorded in EtOH solutions. Recorded $\square_{\max }$ is that of the longest wavelength transition. Fluorescence measurements were taken on a Jobin Yvon Fluorolog fluorescence spectrofluorometer in potassium phosphate $\mathrm{pH} 7.0$ buffer unless otherwise indicated. Quantum yields were measured relative to 9, 10 diphenylanthracene in $\mathrm{EtOH}^{1}$ for probes 1-4 and alcohols 8, 11, 13, and 15, or Coumarin 6 in $\mathrm{EtOH}^{2}$ for probes 5-7 and alcohols 19, 21, and 22. Reported quantum efficiencies are the average of at least three independent preparations of the probes and their cognate alcohols.

\section{Synthesis of Probes 1-7 and the Corresponding Alcohols}

\section{Synthesis of probe 1}
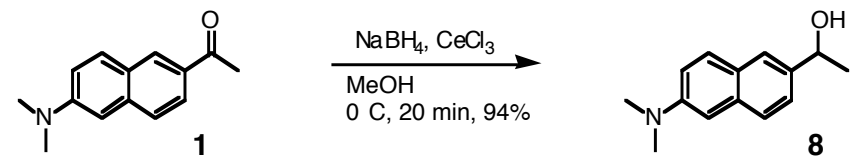

1-(6-Dimethylamino-naphthalen-2-yl)-ethanone (1).

This compound was prepared by a literature procedure and spectral data are consistent with those previously published ${ }^{3}$. 


\section{1-(6-Dimethylamino-naphthalen-2-yl)-ethanol (8).}

$\mathrm{CeCl}_{3} .7 \mathrm{H}_{2} \mathrm{O}(116 \mathrm{mg}, 0.31 \mathrm{mmol})$ was added to a solution of $1(50 \mathrm{mg}, 0.23$ mmol) in $\mathrm{MeOH}(10 \mathrm{ml})$ at $0^{\circ} \mathrm{C}$, followed by addition of $\mathrm{NaBH}_{4}(46 \mathrm{mg}, 1.22 \mathrm{mmol})$. After 20 minutes, the reaction was quenched with a saturated aqueous solution of $\mathrm{NH}_{4} \mathrm{Cl}$ and extracted with $\mathrm{CHCl}_{3}$. Organic layer was dried over $\mathrm{MgSO}_{4}$, evaporated and the crude product was purified by column chromatography on silica gel $\left(\mathrm{CH}_{2} \mathrm{Cl}_{2}\right.$-EtOAc 98:2) to provide pure alcohol (47 $\mathrm{mg}, 94 \%)$.

NMR ${ }^{1} \mathbf{H}\left(300 \mathrm{MHz}, \mathrm{CDCl}_{3}\right) \square \mathrm{ppm}$ :

$7.67(\mathrm{~d}, 1 \mathrm{H}, \mathrm{J} 1=9.0 \mathrm{~Hz}) ; 7.63$ (bs, $1 \mathrm{H}) ; 7.63(\mathrm{~d}, 1 \mathrm{H}, \mathrm{J} 1=8.5 \mathrm{~Hz}) ; 7.37$ (dd, $1 \mathrm{H}$, $\mathrm{J} 1=8.5 \mathrm{~Hz}, \mathrm{~J} 2=1.7 \mathrm{~Hz}) ; 7.15(\mathrm{dd}, 1 \mathrm{H}, \mathrm{J} 1=9.0 \mathrm{~Hz}, \mathrm{~J} 2=2.5 \mathrm{~Hz}) ; 6.90(\mathrm{~d}, 1 \mathrm{H}, \mathrm{J} 1=2.5$ $\mathrm{Hz}) ; 4.99(\mathrm{~m}, 1 \mathrm{H}) ; 3.03(\mathrm{~s}, 6 \mathrm{H}) ; 1.79(\mathrm{~d}, 1 \mathrm{H}, \mathrm{J} 1=3.5 \mathrm{~Hz}), 1.59(\mathrm{~d}, 3 \mathrm{H}, \mathrm{J} 1=6.4 \mathrm{~Hz})$.

NMR ${ }^{13} \mathbf{C}\left(300 \mathrm{MHz}, \mathrm{CDCl}_{3}\right) \square \mathrm{ppm}$ : $148.7 ; 139.3 ; 134.5 ; 128.7 ; 126.6 ; 126.5 ; 124.2 ; 123.6 ; 116.7 ; 106.5 ; 70.6 ; 40.9$; 24.9.

IR $\left(\mathrm{NaCl}, \mathrm{cm}^{-1}\right): 3358,2969,2875,1632,1606,1507,1444,1382,1334,1171,1069$, $968,845,804,676$.

HRMS (FAB): $215.1308\left(\mathrm{C}_{14} \mathrm{H}_{17} \mathrm{ON}, \mathrm{M}\right.$; calc 215.1310).

UV (EtOH): $\square_{\max }=348 \mathrm{~nm}$.

Fluorescence (potassium phosphate $\mathrm{pH} 7.0$ ): $\square_{\mathrm{m}}=429 \mathrm{~nm}, \square_{\mathrm{f}}=0.07$.

\section{Synthesis of probe 2}
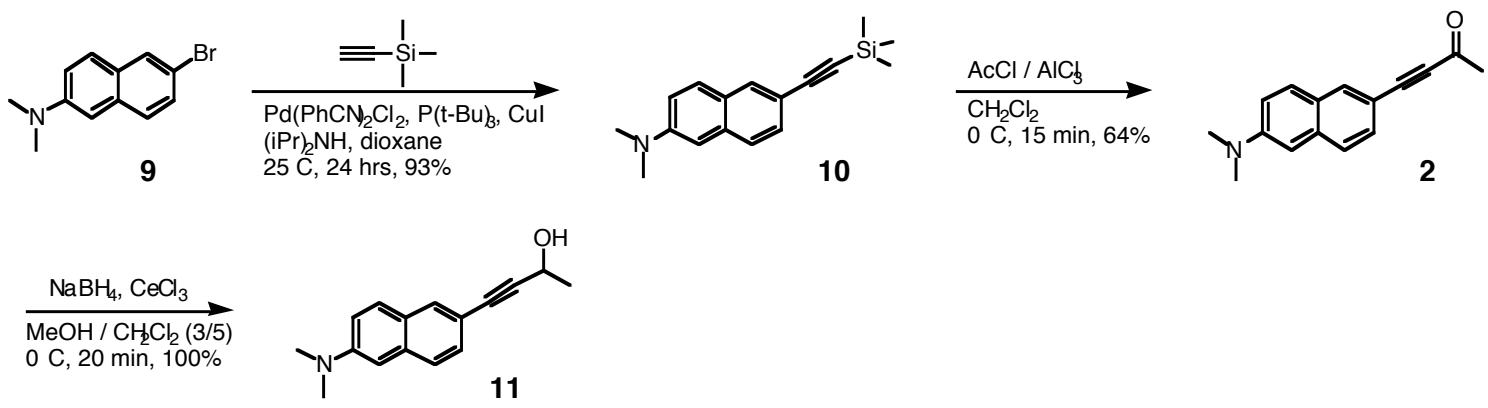

\section{Dimethyl-(6-trimethylsilanylethynyl-naphthalen-2-yl)-amine (10).}

This compound was prepared by the procedure of Buchwald and $\mathrm{Fu}^{4}$ from bromide 9, which was obtained from 2-bromo-6-naphthol according to literature 5 . $\mathrm{Pd}(\mathrm{PhCN})_{2} \mathrm{Cl}_{2}(4.6 \mathrm{mg}, 0.012 \mathrm{mmol})$, CuI (1.5 mg, $\left.0.008 \mathrm{mmol}\right), 9$ (100 mg, 0.400 $\mathrm{mmol})$, dioxane $(1 \mathrm{ml})$, diisopropylamine $(68 \mathrm{Gl}, 0.024 \mathrm{mmol})$ and (trimethylsilyl)acetylene (110 $\square 1,0.800 \mathrm{mmol}$ ) were mixed in a vial under argon and allow to stir $24 \mathrm{hrs}$ at room temperature. The resultant mixture was diluted with EtOAc, washed with brine and dried over $\mathrm{MgSO}_{4}$. Following solvent evaporation and product purification by column chromatography using silica gel and hexanes-EtOAc 98:2, 10 was yielded (99 $\mathrm{mg}, 93 \%)$.

NMR ${ }^{1} \mathbf{H}\left(300 \mathrm{MHz}, \mathrm{CDCl}_{3}\right) \square \mathrm{ppm}:$ 
7.81 (bs, 1H); $7.61(\mathrm{~d}, 1 \mathrm{H} . \mathrm{J} 1=9.1 \mathrm{~Hz}) ; 7.52(\mathrm{~d}, 1 \mathrm{H}, \mathrm{J} 1=8.5 \mathrm{~Hz}) ; 7.36(\mathrm{dd}, 1 \mathrm{H}$, $\mathrm{J} 1=8.5 \mathrm{~Hz}, \mathrm{~J} 2=1.6 \mathrm{~Hz}) ; 7.11(\mathrm{dd}, 1 \mathrm{H}, \mathrm{J} 1=9.1 \mathrm{~Hz}, \mathrm{~J} 2=2.5 \mathrm{~Hz}) ; 6.83(\mathrm{~d}, 1 \mathrm{H}, \mathrm{J} 1=2.5$ $\mathrm{Hz}) ; 3.05$ (s, 6H); 0.27 (s, 9H).

NMR ${ }^{13} \mathbf{C}(300 \mathrm{MHz}$, acetone-d) $\square \mathrm{ppm}$ :

$150.4 ; 135.8 ; 132.3 ; 129.5 ; 129.3 ; 127.0 ; 126.8 ; 117.6 ; 116.5 ; 107.4 ; 106.5 ; 92.9$; $40.6 ; 0.1$.

IR $\left(\mathrm{NaCl}, \mathrm{cm}^{-1}\right): 2960,2901,2812,2147,1629,1598,1247,894,850,838,809$.

HRMS (FAB): $267.1442\left(\mathrm{C}_{17} \mathrm{H}_{21} \mathrm{NSi}, \mathrm{M}\right.$; calc 267.1443).

\section{4-(6-Dimethylamino-naphthalen-2-yl)-but-3-yn-2-one (2).}

$\mathrm{AcCl}(13 \square 1,0.18 \mathrm{mmol})$ was added to a solution of $10(43 \mathrm{mg}, 0.16 \mathrm{mmol})$ in $\mathrm{CH}_{2} \mathrm{Cl}_{2}(2 \mathrm{ml})$ at $0^{\circ} \mathrm{C}$, followed by addition of $\mathrm{AlCl}_{3}(107 \mathrm{mg}, 0.80 \mathrm{mmol})$. After 15 minutes, the reaction was quenched with $\mathrm{H}_{2} \mathrm{O}$ and extracted with EtOAc. After the organic layer was dried over $\mathrm{MgSO}_{4}$, the solvent was removed, and the residue was purified by column chromatography on silica gel (hexanes-EtOAc 98:2) to yield ketone 2 (55 $\mathrm{mg}, 64 \%)$.

NMR ${ }^{1} \mathbf{H}\left(300 \mathrm{MHz}, \mathrm{CDCl}_{3}\right) \square \mathrm{ppm}$ :

7.96 (bs, 1H); $7.66(\mathrm{~d}, 1 \mathrm{H}, \mathrm{J} 1=9.1 \mathrm{~Hz}) ; 7.56(\mathrm{~d}, 1 \mathrm{H}, \mathrm{J}=8.5 \mathrm{~Hz}) ; 7.41(\mathrm{dd}, 1 \mathrm{H}$, $\mathrm{J} 1=8.5 \mathrm{~Hz}, \mathrm{~J} 2=1.6 \mathrm{~Hz}) ; 7.14(\mathrm{dd}, 1 \mathrm{H}, \mathrm{J} 1=9.1 \mathrm{~Hz}, \mathrm{~J} 2=2.5 \mathrm{~Hz}) ; 6.82(\mathrm{~d}, 1 \mathrm{H}, \mathrm{J} 1=2.5$ $\mathrm{Hz}) ; 3.09$ (s, 6H); 2.46 (s, 3H).

NMR ${ }^{13} \mathbf{C}\left(300 \mathrm{MHz}, \mathrm{CDCl}_{3}\right) \square \mathrm{ppm}$ :

$184.6 ; 149.8 ; 135.9 ; 134.6 ; 129.3 ; 129.1 ; 126.3 ; 125.5 ; 116.5 ; 111.9 ; 105.4 ; 93.1$; $88.5 ; 40.4 ; 32.7$.

IR $\left(\mathrm{NaCl}, \mathrm{cm}^{-1}\right): 2892,2817,2180,1667,1625,1507,1354,1280,1190,1168,896,851$, 810.

HRMS (FAB): $237.1138\left(\mathrm{C}_{16} \mathrm{H}_{15} \mathrm{ON}, \mathrm{M}\right.$; calc 237.1154).

UV $(\mathrm{EtOH}): \square_{\max }=389 \mathrm{~nm}$.

Fluorescence (potassium phosphate $\mathrm{pH} 7.0$ ): $448 \mathrm{~nm}, \square_{\mathrm{f}}=0.00$.

4-(6-Dimethylamino-naphthalen-2-yl)-but-3-yn-2-ol (11).

Reduction of $2(20 \mathrm{mg}, 0.084 \mathrm{mmol})$ in $\mathrm{MeOH}-\mathrm{CH}_{2} \mathrm{Cl}_{2} 3: 5(5 \mathrm{ml})$ followed a procedure analogous to that used for the preparation of $\mathbf{8}$. Column chromatography on silica gel $\left(\mathrm{CH}_{2} \mathrm{Cl}_{2}\right)$ afforded alcohol $11(20 \mathrm{mg}, 100 \%)$.

NMR ${ }^{1} \mathbf{H}\left(300 \mathrm{MHz} \mathrm{CDCl}_{3}\right) \square \mathrm{ppm}$ :

$7.77(\mathrm{bs}, 1 \mathrm{H}) ; 7.61(\mathrm{~d}, 1 \mathrm{H}, \mathrm{J} 1=9.1 \mathrm{~Hz}) ; 7.54(\mathrm{~d}, 1 \mathrm{H}, \mathrm{J} 1=8.5 \mathrm{~Hz}) ; 7.33(\mathrm{dd}, 1 \mathrm{H}$, $\mathrm{J} 1=8.5 \mathrm{~Hz}, \mathrm{~J} 2=1.5 \mathrm{~Hz}) ; 7.12(\mathrm{dd}, 1 \mathrm{H} ; \mathrm{J} 1=9.1 \mathrm{~Hz}, \mathrm{~J} 2=2.4 \mathrm{~Hz}) ; 6.83(\mathrm{~d}, 1 \mathrm{H}, \mathrm{J} 1=2.4$ $\mathrm{Hz}) ; 4.78(\mathrm{~m}, 1 \mathrm{H}) ; 3.05(\mathrm{~s}, 6 \mathrm{H}) ; 1.88(\mathrm{~d}, 1 \mathrm{H}, \mathrm{J} 1=4.8 \mathrm{~Hz}) ; 1.57$ (d, 3H, J1=6.5 Hz).

NMR ${ }^{13} \mathbf{C}\left(300 \mathrm{MHz}, \mathrm{CDCl}_{3}\right) \square \mathrm{ppm}$ : $149.1 ; 134.5 ; 131.4 ; 128.8 ; 128.7 ; 126.1 ; 126.0 ; 116.6 ; 115.3 ; 105.9 ; 89.9 ; 85.0$; $59.0 ; 40.6 ; 24.5$.

IR $\left(\mathrm{NaCl}, \mathrm{cm}^{-1}\right): 3346,2982,2930,2882,1628,1598,1505,1389,1101,1072,1035$, 893, 848, 809.

HRMS (FAB): $239.1305\left(\mathrm{C}_{16} \mathrm{H}_{17} \mathrm{ON}, \mathrm{M}\right.$; calc 239.1310).

UV $(\mathrm{EtOH}): \square_{\max }=361 \mathrm{~nm}$.

Fluorescence (potassium phosphate $\mathrm{pH} 7.0$ ): $440 \mathrm{~nm}, \square_{\mathrm{f}}=0.08$. 


\section{Synthesis of probe 3}

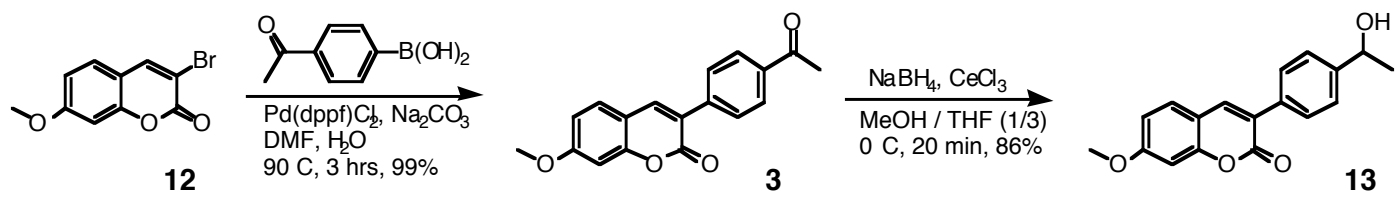

\section{3-(4-Acetyl-phenyl)-7-methoxy-coumarin (3).}

Bromide 12 (400 $\mathrm{mg}, 1.57 \mathrm{mmol})$, obtained by bromination of 7-methoxycoumarin, was mixed with 4-acetylphenylboronic acid (283 $\mathrm{mg}, 1.72 \mathrm{mmol}$ ), $\mathrm{PdCl}_{2} \mathrm{dppf}$ (40 mg, $\left.0.047 \mathrm{mmol}\right), \mathrm{Na}_{2} \mathrm{CO}_{3}(831 \mathrm{mg}, 7.84 \mathrm{mmol}), \mathrm{H}_{2} \mathrm{O}(3.92 \mathrm{ml})$ and DMF $(16 \mathrm{ml})$ under argon. The resulting mixture was heated to $90^{\circ} \mathrm{C}$ and stirred until completion $(3 \mathrm{hrs})$. The cooled mixture was then diluted with water and extracted with $\mathrm{CH}_{2} \mathrm{Cl}_{2}$. Combined organic fractions were dried over $\mathrm{MgSO}_{4}$. Following the evaporation of solvent, the residue was purified by column chromatography on silica gel $\left(\mathrm{CH}_{2} \mathrm{Cl}_{2}\right)$ to afford desired product 3 (456 $\mathrm{mg}, 99 \%)$.

NMR ${ }^{1} \mathbf{H}\left(300 \mathrm{MHz}, \mathrm{CDCl}_{3}\right) \square \mathrm{ppm}$ :

$8.00(\mathrm{~m}, 2 \mathrm{H}) ; 7.83(\mathrm{~m}, 2 \mathrm{H}) ; 7.77(\mathrm{bs}, 1 \mathrm{H}) ; 7.46(\mathrm{~d}, 1 \mathrm{H}, \mathrm{J} 1=8.4 \mathrm{~Hz}) ; 6.88(\mathrm{~m}, 2 \mathrm{H})$; $3.90(\mathrm{~s}, 3 \mathrm{H}) ; 2.64(\mathrm{~s}, 3 \mathrm{H})$.

NMR ${ }^{13} \mathbf{C}\left(300 \mathrm{MHz}, \mathrm{CDCl}_{3}\right) \square \mathrm{ppm}$ :

$197.6 ; 163.1 ; 160.5 ; 155.6 ; 141.0 ; 139.6 ; 136.6 ; 129.2 ; 128.5 ; 128.4 ; 123.5$; $113.1 ; 113.1 ; 100.4 ; 55.9 ; 26.7$.

IR $\left(\mathrm{NaCl}, \mathrm{cm}^{-1}\right): 3070,2962,1710,1670,1613,1505,1442,1360,1275,1198,1122$, 1022, 929, 859, 829, 776.

HRMS (FAB): $295.0967\left(\mathrm{C}_{18} \mathrm{H}_{15} \mathrm{O}_{4}, \mathrm{M}+1\right.$; calc 295.0970).

UV (EtOH): $\square_{\max }=348 \mathrm{~nm}$.

Fluorescence (potassium phosphate $\mathrm{pH} 7.0$ ): $462 \mathrm{~nm}, \square_{\mathrm{f}}=0.00$.

\section{3-[4-(1-Hydroxy-ethyl)-phenyl]-7-methoxy-coumarin (13).}

Reduction of 3 (42 mg, $0.14 \mathrm{mmol})$ in MeOH-THF 1:3 (15ml) proceeded as described for the preparation of $\mathbf{8}$. Column chromatography on silica gel (eluent gradient: $\mathrm{CH}_{2} \mathrm{Cl}_{2}$ to $\mathrm{CH}_{2} \mathrm{Cl}_{2}$-EtOAc 8:2) afforded alcohol 13 (36 mg, 86\%).

NMR ${ }^{1} \mathbf{H}\left(300 \mathrm{MHz} \mathrm{CDCl}_{3}\right) \square \mathrm{ppm}$ :

$7.75(\mathrm{~s}, 1 \mathrm{H}) ; 7.67(\mathrm{~m}, 2 \mathrm{H}) ; 7.44(\mathrm{~m}, 3 \mathrm{H}) ; 4.95(\mathrm{~m}, 1 \mathrm{H}) ; 3.89(\mathrm{~s}, 3 \mathrm{H}) ; 1.85(\mathrm{~d}, 1 \mathrm{H}$, $\mathrm{J} 1=3.4 \mathrm{~Hz}) ; 1.52(\mathrm{~d}, 3 \mathrm{H}, \mathrm{J} 1=6.4 \mathrm{~Hz})$.

NMR ${ }^{13} \mathbf{C}\left(300 \mathrm{MHz}, \mathrm{CDCl}_{3}\right) \square \mathrm{ppm}$ :

$162.5 ; 160.9 ; 155.2 ; 146.1 ; 139.8 ; 134.0 ; 128.8 ; 128.4 ; 125.4 ; 124.4 ; 113.3$; $112.7 ; 100.3 ; 70.0 ; 55.7 ; 25.1$.

IR $\left(\mathrm{NaCl}, \mathrm{cm}^{-1}\right): 3415,2971,1719,1611,1057,1443,1364,1271,1202,1163,1120$, 1089, 1026, 832 .

HRMS (FAB): $297.1112\left(\mathrm{C}_{18} \mathrm{H}_{17} \mathrm{O}_{4}, \mathrm{M}+1\right.$; calc 297.1127).

UV $(\mathrm{EtOH})$ : $\square_{\max }=342 \mathrm{~nm}$.

Fluorescence (potassium phosphate $\mathrm{pH} 7.0$ ): $429 \mathrm{~nm}, \square_{\mathrm{f}}=0.12$.

\section{Synthesis of probe 4}



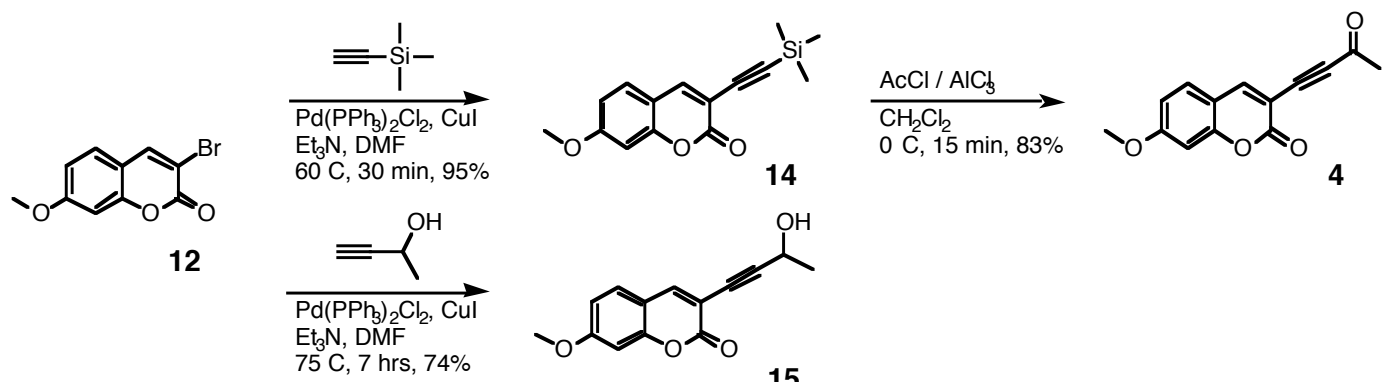

12

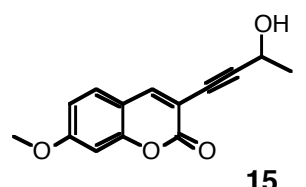

15

\section{7-Methoxy-3-trimethylsilanylethynyl-coumarin (14).}

$\mathrm{PdCl}_{2}\left(\mathrm{PPh}_{3}\right)_{2}(28 \mathrm{mg}, 0.04 \mathrm{mmol}), \mathrm{CuI}(8 \mathrm{mg}, 0.04 \mathrm{mmol}), \mathrm{Et}_{3} \mathrm{~N}(278 \square \mathrm{l}, 2.00$ mmol) and (trimethylsilyl)acetylene $(138 \square \mathrm{l}, 1.50 \mathrm{mmol})$ were added to a solution of bromide $12(255 \mathrm{mg}, 1.00 \mathrm{mmol})$ in dry DMF $(10 \mathrm{ml})$ under argon. The resulting solution was heated to $60^{\circ} \mathrm{C}$ and allowed to react 30 minutes. The mixture was then cooled, diluted with water, and extracted with $\mathrm{CH}_{2} \mathrm{Cl}_{2}$. The organic fractions were then combined and dried over $\mathrm{MgSO}_{4}$. Removal of solvent in vacuo and purification of the residue by column chromatography on silica gel $\left(\mathrm{CH}_{2} \mathrm{Cl}_{2}\right)$ afforded product $14(259 \mathrm{mg}, 95 \%)$.

NMR ${ }^{1} \mathbf{H}\left(300 \mathrm{MHz}, \mathrm{CDCl}_{3}\right) \square \mathrm{ppm}$ :

$7.82(\mathrm{~s}, 1 \mathrm{H}) ; 7.32(\mathrm{~d}, 1 \mathrm{H}, \mathrm{J} 1=8.6 \mathrm{~Hz}) ; 6.83(\mathrm{dd}, 1 \mathrm{H}, \mathrm{J} 1=8.6 \mathrm{~Hz}, \mathrm{~J} 2=2.4 \mathrm{~Hz}) ; 6.78$

$(\mathrm{d}, 1 \mathrm{H}, \mathrm{J} 1=2.4 \mathrm{~Hz}) ; 3.86(\mathrm{~s}, 3 \mathrm{H}) ; 0.26(\mathrm{~s}, 9 \mathrm{H})$.

NMR ${ }^{13} \mathbf{C}(300 \mathrm{MHz}$, acetone-d) $\square$ ppm:

$164.6 ; 159.5 ; 156.5 ; 147.5 ; 130.4 ; 113.8 ; 113.2 ; 109.3 ; 101.3 ; 100.2 ; 99.8 ; 56.5$; -0.2 .

IR $\left(\mathrm{NaCl}, \mathrm{cm}^{-1}\right): 3040,2961,2840,1721,1600,1441,1368,1272,1247,1034,973,831$, 807,765 .

HRMS (FAB): $272.0869\left(\mathrm{C}_{15} \mathrm{H}_{16} \mathrm{O}_{3} \mathrm{Si}\right.$, M; calc 272.0869).

7-Methoxy-3-(3-oxo-but-1-ynyl)-coumarin (4).

Compound 14 (103 $\mathrm{mg}, 0.38 \mathrm{mmol}$ ) was converted into ketone $\mathbf{4}$ by the procedure used for the preparation of $\mathbf{2}$. Column chromatography of the crude product on silica gel $\left(\mathrm{CH}_{2} \mathrm{Cl}_{2}\right)$ provided $4(76 \mathrm{mg}, 83 \%)$.

NMR ${ }^{1} \mathbf{H}\left(300 \mathrm{MHz}, \mathrm{CDCl}_{3}\right) \square \mathrm{ppm}$ :

8.00 (bs, 1H); 7.40 (d, 1H, J1=8.7 Hz); $6.88(\mathrm{dd}, 1 \mathrm{H}, \mathrm{J} 1=8.7 \mathrm{~Hz}, \mathrm{~J} 2=2.3 \mathrm{~Hz}) ; 6.81$ $(\mathrm{d}, 1 \mathrm{H}, \mathrm{J} 1=2.3 \mathrm{~Hz}) ; 3.90(\mathrm{~s}, 3 \mathrm{H}) ; 2.47(\mathrm{~s}, 3 \mathrm{H})$.

NMR ${ }^{13} \mathbf{C}\left(300 \mathrm{MHz}, \mathrm{CDCl}_{3}\right) \square \mathrm{ppm}$ :

184.1, 164.7; 158.9; 156.3; 149.8; 129.7; 113.8; 112.1; 106.0; 100.9; 92.2; 84.1; $56.0 ; 32.6$.

IR $\left(\mathrm{NaCl}, \mathrm{cm}^{-1}\right): 3046,2197,1725,1664,1617,1596,1557,1504,1368,1273,1250$, $1152,1116,1019,836$.

HRMS (FAB): $242.0572\left(\mathrm{C}_{14} \mathrm{H}_{10} \mathrm{O}_{4}, \mathrm{M}+1\right.$; calc. 242.0579) .

UV (EtOH): $\square_{\max }=368 \mathrm{~nm}$.

Fluorescence (potassium phosphate $\mathrm{pH} 7.0$ ): $416 \mathrm{~nm}, \square_{\mathrm{f}}=0.00$.

\section{3-(3-Hydroxy-but-1-ynyl)-7-methoxy-coumarin (15).}

Alcohol 15 was prepared by Sonogashira coupling of bromide $12(100 \mathrm{mg}, 0.39$ $\mathrm{mmol}$ ) and but-3-yn-2-ol ( $32 \square \mathrm{l}, 0.43 \mathrm{mmol})$ under conditions similar to that used for the 
preparation of 14. After 7 hours at $75^{\circ} \mathrm{C}$, the reaction was complete. The crude alcohol was purified by column chromatography on silica gel $\left(\mathrm{CH}_{2} \mathrm{Cl}_{2}-\mathrm{EtOAc} 95: 5\right)$ to afford product 15 (96 $\mathrm{mg}, 74 \%)$.

NMR ${ }^{1} \mathbf{H}\left(300 \mathrm{MHz}, \mathrm{CDCl}_{3}\right) \square \mathrm{ppm}$ :

7.81 (bs, 1H); 7.35 (d, 1H, J1=8.6 Hz); 6.86 (dd, 1H, J1=8.6 Hz, J2=2.4 Hz); 6.81 $(\mathrm{d}, 1 \mathrm{H}, \mathrm{J} 1=2.4 \mathrm{~Hz}) ; 4.79$ (m, 1H); 3.88 (s, 3H); 2.26 (d, 1H, J1=5.2 Hz); 1.56 (d, $3 \mathrm{H}, \mathrm{J} 1=6.6 \mathrm{~Hz})$.

NMR ${ }^{13} \mathbf{C}\left(300 \mathrm{MHz}, \mathrm{CDCl}_{3}\right) \square \mathrm{ppm}$ :

$163.3 ; 160.1 ; 155.2 ; 145.5 ; 128.8 ; 113.2 ; 112.4 ; 108.6 ; 100.7 ; 96.7 ; 77.9 ; 58.7$; $55.8 ; 24.0$.

IR $\left(\mathrm{NaCl}, \mathrm{cm}^{-1}\right): 3414,2983,2939,2843,1733,1618,1506,1365,1269,1121,1024$, 768.

HRMS (FAB): $244.0744\left(\mathrm{C}_{14} \mathrm{H}_{12} \mathrm{O}_{4}, \mathrm{M}\right.$; calc 244.0736).

UV $(\mathrm{EtOH}): \square_{\max }=346 \mathrm{~nm}$.

Fluorescence (potassium phosphate $\mathrm{pH} 7.0$ ): $420 \mathrm{~nm}, \square_{\mathrm{f}}=0.18$.

\section{Synthesis of probe 5}
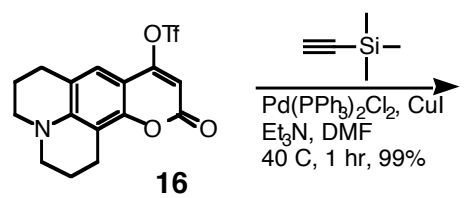

$\mathrm{HgSO}_{4}, \mathrm{H}_{2} \mathrm{SO}_{4}$
$\mathrm{H}_{2} \mathrm{O} / \mathrm{THF} \mathrm{(1/4)}$
$\underset{90^{\circ} \mathrm{C}, 2 \mathrm{hrs}, 46 \%}{\longrightarrow}$
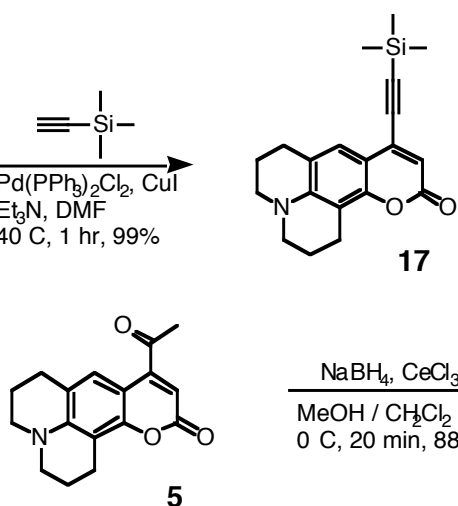

17
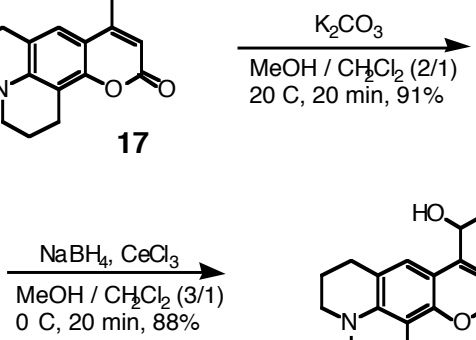

$0^{\circ} \mathrm{C}, 20 \mathrm{~min}, 88 \%$

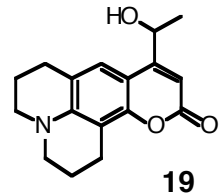

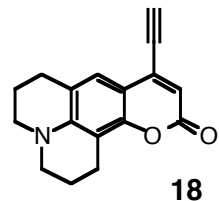

18

\section{8-Trimethylsilanylethynyl-2,3,5,6-tetrahydro- $1 H, 4 H$-11-oxa-3a-aza- benzo[de]anthracen-10-one (17).}

Triflate 16 (707mg, $1.82 \mathrm{mmol})$, obtained from 8-hydroxyjulolidine according to the literature ${ }^{6}$, was coupled with (trimethylsilyl)acetylene (377 $\square 1,2.72 \mathrm{mmol}$ ) under conditions described for the preparation of 14. The reaction was complete after $1 \mathrm{hr}$ at $40^{\circ} \mathrm{C}$. Column chromatography on silica gel $\left(\mathrm{CH}_{2} \mathrm{Cl}_{2}\right)$ provided desired product 17 (607 mg, 99\%).

NMR ${ }^{1} \mathbf{H}\left(300 \mathrm{MHz}, \mathrm{CDCl}_{3}\right) \square \mathrm{ppm}:$

$7.16(\mathrm{~s}, 1 \mathrm{H}) ; 6.11(\mathrm{~s}, 1 \mathrm{H}) ; 3.26(\mathrm{~m}, 4 \mathrm{H}) ; 2.83(\mathrm{~m}, 4 \mathrm{H}) ; 1.97(\mathrm{~m}, 4 \mathrm{H}) ; 0.31(\mathrm{~s}, 9 \mathrm{H})$. NMR ${ }^{13} \mathbf{C}\left(300 \mathrm{MHz}, \mathrm{CDCl}_{3}\right) \square$ ppm:

$161.8 ; 151.1 ; 146.1 ; 137.0 ; 123.5 ; 118.3 ; 110.8 ; 107.6 ; 106.6 ; 106.3 ; 98.8 ; 49.9$; $49.4 ; 27.6 ; 21.4 ; 20.4 ; 20.2 ;-0.4$.

IR $\left(\mathrm{NaCl}, \mathrm{cm}^{-1}\right): 2946,2848,1701,1612,1546,1511,1421,1367,1310,1245,1184$, 843.

HRMS (FAB): $338.1574\left(\mathrm{C}_{20} \mathrm{H}_{24} \mathrm{O}_{2} \mathrm{NSi}, \mathrm{M}+1\right.$; calc 338.1576). 


\section{8-Ethynyl-2,3,5,6-tetrahydro-1H, $4 H$-11-oxa-3a-aza-benzo[de]anthracen-10-one}

(18).

Powdered $\mathrm{K}_{2} \mathrm{CO}_{3}(600 \mathrm{mg})$ was added to a solution of $17(580 \mathrm{mg}, 1.72 \mathrm{mmol})$ in $\mathrm{MeOH}-\mathrm{CH}_{2} \mathrm{Cl}_{2} 2: 1(30 \mathrm{ml})$. The mixture was stirred at room temperature until the reaction was complete (20 min). Reaction mixture was diluted with $\mathrm{CHCl}_{3}$, filtered, and washed with brine. The resultant organic layers were combined and dried over $\mathrm{MgSO}_{4}$, after which the solvent was removed in vacuo. Purification by column chromatography on silica gel (eluent gradient: $\mathrm{CH}_{2} \mathrm{Cl}_{2}$ to $\mathrm{CH}_{2} \mathrm{Cl}_{2}$-EtOAc 95:5) afforded terminal alkyne 18 (416 mg, 91\%).

NMR ${ }^{1} \mathbf{H}\left(300 \mathrm{MHz}, \mathrm{CDCl}_{3}\right) \square \mathrm{ppm}:$

$7.19(\mathrm{~s}, 1 \mathrm{H}) ; 6.16(\mathrm{~s}, 1 \mathrm{H}) ; 3.58(\mathrm{~s}, 1 \mathrm{H}) ; 3.27(\mathrm{~m}, 4 \mathrm{H}) ; 2.87(\mathrm{~m}, 2 \mathrm{H}) ; 2.78(\mathrm{~m}, 2 \mathrm{H})$; $1.97(\mathrm{~m}, 4 \mathrm{H})$.

NMR ${ }^{13} \mathbf{C}\left(300 \mathrm{MHz}, \mathrm{CDCl}_{3}\right) \square \mathrm{ppm}$ :

$161.6 ; 151.1 ; 146.3 ; 136.3 ; 123.4 ; 118.5 ; 111.7 ; 107.6 ; 106.4 ; 87.5 ; 78.0 ; 49.9$; $49.5 ; 27.5 ; 21.3 ; 20.4 ; 20.2$.

IR $\left(\mathrm{NaCl}, \mathrm{cm}^{-1}\right): 3221,2931,2838,2103,1699,1616,1519,1428,1371,1311,1176$, 826.

HRMS (FAB): $266.1193\left(\mathrm{C}_{17} \mathrm{H}_{16} \mathrm{O}_{2} \mathrm{~N}, \mathrm{M}+1\right.$; calc 266.1181).

\section{8-Acetyl-2,3,5,6-tetrahydro-1H, $4 H$-11-oxa-3a-aza-benzo[de]anthracen-10-one (5).}

$\mathrm{HgSO}_{4}(112 \mathrm{mg}, 0.38 \mathrm{mmol})$ was added to a solution of $18(100 \mathrm{mg}, 0.38 \mathrm{mmol})$ in THF (8 ml), followed by addition of conc. $\mathrm{H}_{2} \mathrm{SO}_{4}(105 \square \mathrm{l}, 1.88 \mathrm{mmol})$ in $\mathrm{H}_{2} \mathrm{O}(2 \mathrm{ml})$. The reaction mixture was heated in a sealed tube at $90^{\circ} \mathrm{C}$ for $2 \mathrm{hrs}$. After cooling to room temperature, a spatula tip of $\mathrm{NaHCO}_{3}$ was added and the mixture was evaporated to dryness. $\mathrm{MgSO}_{4}$ was added and the residual solids were washed thoroughly with $\mathrm{CHCl}_{3}$. The solvent was the evaporated and the residue purified by column chromatography on silica gel $\left(\mathrm{CH}_{2} \mathrm{Cl}_{2}-\mathrm{Et}_{2} \mathrm{O}\right.$ 95:5) yielding ketone 5 (49 $\mathrm{mg}, 46 \%$ ).

NMR ${ }^{1} \mathbf{H}\left(300 \mathrm{MHz}, \mathrm{CDCl}_{3}\right) \square \mathrm{ppm}$ :

$7.18(\mathrm{~s}, 1 \mathrm{H}) ; 6.13(\mathrm{~s}, 1 \mathrm{H}) ; 3.27(\mathrm{~m}, 4 \mathrm{H}) ; 2.88(\mathrm{~m}, 2 \mathrm{H}) ; 2.74(\mathrm{~m}, 2 \mathrm{H}) ; 2.55(\mathrm{~s}, 3 \mathrm{H})$; $1.96(\mathrm{~m}, 4 \mathrm{H})$.

NMR ${ }^{13} \mathbf{C}\left(300 \mathrm{MHz}, \mathrm{CDCl}_{3}\right) \square \mathrm{ppm}$ : $200.4 ; 162.1 ; 152.1 ; 150.8 ; 146.2 ; 123.2 ; 118.7 ; 106.8 ; 106.8 ; 103.7 ; 49.9 ; 49.4$; $29.7 ; 27.6 ; 21.3 ; 20.4 ; 20.3$.

IR $\left(\mathrm{NaCl}, \mathrm{cm}^{-1}\right): 2933,2844,1694,1611,1544,1525,1434,1373,1352,1311,1232$, $1170,1148$.

HRMS (FAB): $283.1195\left(\mathrm{C}_{17} \mathrm{H}_{17} \mathrm{O}_{3} \mathrm{~N}, \mathrm{M}\right.$; calc 283.1208).

UV $(\mathrm{EtOH}): \square_{\max }=418 \mathrm{~nm}$.

Fluorescence (potassium phosphate $\mathrm{pH} 7.0$ ): $520 \mathrm{~nm}, \square_{\mathrm{f}}=0.00$.

\section{8-(1-Hydroxy-ethyl)-2,3,5,6-tetrahydro-1H, $4 H$-11-oxa-3a-aza-benzo[de]anthracen- 10-one (19).}

Reduction of 5 (16 mg, $0.056 \mathrm{mmol})$ in $\mathrm{MeOH}-\mathrm{CH}_{2} \mathrm{Cl}_{2} 3: 1$ (5ml) proceeded by previously described procedures (used for preparation of 8). Column chromatography on silica gel (eluent gradient: $\mathrm{CH}_{2} \mathrm{Cl}_{2}$ to $\mathrm{CH}_{2} \mathrm{Cl}_{2}$-EtOAc 9:1) afforded alcohol 19 (14 mg, $88 \%)$.

NMR ${ }^{1} \mathbf{H}\left(300 \mathrm{MHz}, \mathrm{CDCl}_{3}\right) \square \mathrm{ppm}:$ 
$7.01(\mathrm{~s}, 1 \mathrm{H}) ; 6.24(\mathrm{~s}, 1 \mathrm{H}) ; 5.14(\mathrm{~m}, 1 \mathrm{H}) ; 3.26(\mathrm{~m}, 4 \mathrm{H}) ; 2.87(\mathrm{~m}, 2 \mathrm{H}) ; 2.77(\mathrm{~m}$, $2 \mathrm{H}) ; 2.07(\mathrm{~d}, 1 \mathrm{H}, \mathrm{J} 1=3.8 \mathrm{~Hz}) ; 2.10(\mathrm{~m}, 4 \mathrm{H}) ; 1.55(\mathrm{~d}, 3 \mathrm{H}, \mathrm{J} 1=6.5 \mathrm{~Hz})$.

NMR ${ }^{13} \mathbf{C}\left(300 \mathrm{MHz}, \mathrm{CDCl}_{3}\right) \square \mathrm{ppm}$ :

$163.0 ; 159.4 ; 151.4 ; 145.6 ; 121.0 ; 118.0 ; 107.1 ; 105.9 ; 103.8 ; 65.9 ; 49.9 ; 49.5$;

$27.8 ; 23.6 ; 21.5 ; 20.6 ; 20.5$.

IR $\left(\mathrm{NaCl}, \mathrm{cm}^{-1}\right): 3396,2936,2843,1688,1611,1554,1520,1433,1372,1311,1183$, 1133.

HRMS (FAB): $286.1437\left(\mathrm{C}_{17} \mathrm{H}_{20} \mathrm{O}_{3} \mathrm{~N}, \mathrm{M}+1\right.$; calc 286.1443).

UV $(\mathrm{EtOH}): \square_{\max }=398 \mathrm{~nm}$.

Fluorescence (potassium phosphate $\mathrm{pH} 7.0$ ): $509 \mathrm{~nm}, \square_{\mathrm{f}}=0.21$.

\section{Synthesis of probe 6}
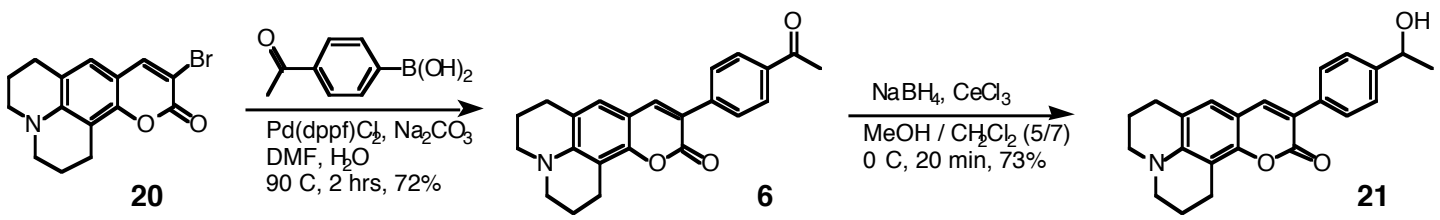

9-(4-Acetyl-phenyl)-2,3,5,6-tetrahydro-1H, $4 H$-11-oxa-3a-aza-benzo[de]anthracen10-one (6).

Bromide 20 (100 mg, $0.31 \mathrm{mmol}$ ), obtained by bromination of coumarin $6 \mathrm{H}$, was coupled with 4-acetylphenylboronic acid $(77 \mathrm{mg}, 0.46 \mathrm{mmol})$, under similar conditions as those used for preparation of $\mathbf{3}$. Reaction was complete after $2 \mathrm{hrs}$ at $90^{\circ} \mathrm{C}$. Column chromatography on silica gel (eluent gradient: $\mathrm{CH}_{2} \mathrm{Cl}_{2}$ to $\mathrm{CH}_{2} \mathrm{Cl}_{2}$-EtOAc 95:5) provided desired ketone 6 (81 mg, 72\%).

NMR ${ }^{1} \mathbf{H}\left(300 \mathrm{MHz}, \mathrm{CDCl}_{3}\right) \square \mathrm{ppm}$ :

$7.96(\mathrm{~m}, 2 \mathrm{H}) ; 7.81(\mathrm{~m}, 2 \mathrm{H}) ; 7.68(\mathrm{~s}, 1 \mathrm{H}) ; 6.91(\mathrm{~s}, 1 \mathrm{H}) ; 3.29(\mathrm{~m}, 4 \mathrm{H}) ; 2.93(\mathrm{~m}$, $2 \mathrm{H}) ; 2.77(\mathrm{~m}, 2 \mathrm{H}) ; 2.61(\mathrm{~s}, 3 \mathrm{H}) ; 1.98(\mathrm{~m}, 4 \mathrm{H})$.

NMR ${ }^{13} \mathbf{C}\left(300 \mathrm{MHz}, \mathrm{CDCl}_{3}\right) \square \mathrm{ppm}$ :

$197.7 ; 161.4 ; 151.5 ; 146.3 ; 141.7 ; 141.0 ; 135.6 ; 128.3 ; 128.0 ; 125.4 ; 118.7$;

$118.0 ; 108.7 ; 106.1 ; 50.0 ; 49.6 ; 27.4 ; 26.6 ; 21.4 ; 20.4 ; 20.2$.

IR $\left(\mathrm{NaCl}, \mathrm{cm}^{-1}\right): 2941,2845,1699,1677,1616,1594,1563,1518,1360,1306,1269$, $1213,1171$.

HRMS (FAB): $359.1527\left(\mathrm{C}_{23} \mathrm{H}_{21} \mathrm{O}_{3} \mathrm{~N}, \mathrm{M}\right.$; calc 359.1521).

UV $(\mathrm{EtOH}): \square_{\max }=435 \mathrm{~nm}$.

Fluorescence (potassium phosphate $\mathrm{pH} 7.0$ ): $511 \mathrm{~nm}, \square_{\mathrm{f}}=0.01$.

9-[4-(1-Hydroxy-ethyl)-phenyl]-2,3,5,6-tetrahydro-1H, $4 H$-11-oxa-3a-azabenzo[de]anthracen-10-one (21).

Reduction of $6(15 \mathrm{mg}, 0.041 \mathrm{mmol})$ in $\mathrm{MeOH}-\mathrm{CH}_{2} \mathrm{Cl}_{2} 5: 7(6 \mathrm{ml})$ by the procedure used for preparation of $\mathbf{8}$ and recrystallization from $\mathrm{CHCl}_{3}$-hexanes afforded alcohol 21 (11 mg, 73\%).

NMR ${ }^{1} \mathbf{H}\left(300 \mathrm{MHz}, \mathrm{CDCl}_{3}\right) \square \mathrm{ppm}$ : 
$7.66(\mathrm{~m}, 2 \mathrm{H}) ; 7.58(\mathrm{~s}, 1 \mathrm{H}) ; 7.40(\mathrm{~m}, 2 \mathrm{H}) ; 6.88(\mathrm{~s}, 1 \mathrm{H}) ; 4.92(\mathrm{q}, 1 \mathrm{H}, \mathrm{J} 1=6.4 \mathrm{~Hz})$;

$3.28(\mathrm{~m}, 4 \mathrm{H}) ; 2.92(\mathrm{~m}, 2 \mathrm{H}) ; 2.76(\mathrm{~m}, 2 \mathrm{H}) ; 1.98(\mathrm{~m}, 4 \mathrm{H}) ; 1.81$ (bs, $1 \mathrm{H}) ; 1.51(\mathrm{~d}$, $3 \mathrm{H}, \mathrm{J} 1=6.4 \mathrm{~Hz})$.

NMR ${ }^{13} \mathbf{C}\left(300 \mathrm{MHz}, \mathrm{CDCl}_{3}\right) \square \mathrm{ppm}$ :

$161.9 ; 151.2 ; 145.8 ; 145.1 ; 140.8 ; 135.3 ; 128.3 ; 125.3 ; 125.1 ; 119.6 ; 118.5$; $109.0 ; 106.3 ; 70.2 ; 50.0 ; 49.6 ; 27.5 ; 25.1 ; 21.5 ; 20.6 ; 20.3$.

IR $\left(\mathrm{NaCl}, \mathrm{cm}^{-1}\right): 3408,2930,2844,1694,1615,1599,1564,1519,1309,1209,1170$, $839,748$.

HRMS (FAB): $361.1673\left(\mathrm{C}_{23} \mathrm{H}_{23} \mathrm{O}_{3} \mathrm{~N}\right.$, M; calc 361.1678).

UV (EtOH): $\square_{\max }=422 \mathrm{~nm}$.

Fluorescence (potassium phosphate $\mathrm{pH} 7.0$ ): $509 \mathrm{~nm}, \square_{\mathrm{f}}=0.14$.

\section{Synthesis of probe 7}

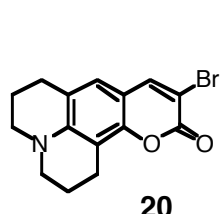

20

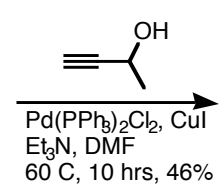

$60^{\circ} \mathrm{C}, 10 \mathrm{hrs}, 46 \%$

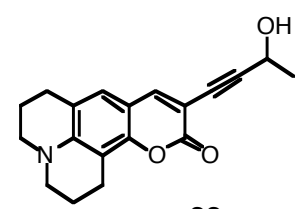

22

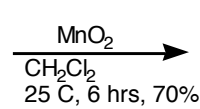

9-(3-Hydroxy-but-1-ynyl)-2,3,5,6-tetrahydro-1H, $4 H$-11-oxa-3a-aza-

\section{benzo[de]anthracen-10-one (22).}

Alcohol 22 was prepared by Sonogashira coupling of bromide 20 (100 mg, 0.31 $\mathrm{mmol})$ and but-3-yn-2-ol $(26 \square 1,0.34 \mathrm{mmol})$ as described for the preparation of 14 . The reaction was stopped after $10 \mathrm{hrs}$ at $60^{\circ} \mathrm{C}$. Column chromatography on silica gel (eluent gradient: $\mathrm{CH}_{2} \mathrm{Cl}_{2}$ to $\mathrm{CH}_{2} \mathrm{Cl}_{2}$-EtOAc 9:1) provided 22 (45 mg, 46\%).

NMR ${ }^{1} \mathbf{H}\left(300 \mathrm{MHz}, \mathrm{CDCl}_{3}\right) \square \mathrm{ppm}$ :

$7.60(\mathrm{~s}, 1 \mathrm{H}) ; 6.78(\mathrm{~s}, 1 \mathrm{H}) ; 4.77(\mathrm{~m}, 1 \mathrm{H}) ; 3.28(\mathrm{~m}, 4 \mathrm{H}) ; 2.87(\mathrm{~m}, 2 \mathrm{H}) ; 2.75(\mathrm{~m}$, $2 \mathrm{H}) ; 2.14(\mathrm{~d}, 1 \mathrm{H}, \mathrm{J} 1=4.9 \mathrm{~Hz}) ; 1.97(\mathrm{~m}, 4 \mathrm{H}) ; 1.54(\mathrm{~d}, 3 \mathrm{H}, \mathrm{J} 1=6.6 \mathrm{~Hz})$.

NMR ${ }^{13} \mathbf{C}\left(300 \mathrm{MHz}, \mathrm{CDCl}_{3}\right) \square \mathrm{ppm}$ :

$161.6 ; 151.3 ; 146.6 ; 146.4 ; 125.0 ; 118.9 ; 108.1 ; 106.4 ; 102.8 ; 94.7 ; 79.3 ; 58.9$; $50.1 ; 49.7 ; 27.4 ; 24.1 ; 21.3 ; 20.4 ; 20.2$.

IR $\left(\mathrm{NaCl}, \mathrm{cm}^{-1}\right): 3397,2934,2849,1709,1692,1616,1594,1518,1360,1309,1290$, $1169,765$.

HRMS (FAB): $309.1365\left(\mathrm{C}_{19} \mathrm{H}_{19} \mathrm{O}_{3} \mathrm{~N}, \mathrm{M}\right.$; calc 309.1365).

UV $(\mathrm{EtOH}): \square_{\max }=429 \mathrm{~nm}$.

Fluorescence (potassium phosphate $\mathrm{pH} 7.0$ ): $508 \mathrm{~nm}, \square_{\mathrm{f}}=0.35$.

\section{9-(3-Oxo-but-1-ynyl)-2,3,5,6-tetrahydro-1H, 4H-11-oxa-3a-aza-benzo[de]anthracen- 10-one (7).}

To alcohol 22 (30 mg, $0.097 \mathrm{mmol})$ dissolved in dry $\mathrm{CH}_{2} \mathrm{Cl}_{2}(3 \mathrm{ml})$ was added powdered $\mathrm{MnO}_{2}(150 \mathrm{mg})$ at room temperature. The resulting suspension was stirred until the reaction was complete $(6 \mathrm{hrs})$. The subsequent mixture was filtered through Celite, dried in vacuo, and purified by column chromatography on silica gel (eluent gradient: $\mathrm{CH}_{2} \mathrm{Cl}_{2}$ to $\mathrm{CH}_{2} \mathrm{Cl}_{2}$-EtOAc 98:2) to afford 7 (21 mg, 70\%).

NMR ${ }^{1} \mathbf{H}\left(300 \mathrm{MHz}, \mathrm{CDCl}_{3}\right) \square \mathrm{ppm}$ : 
$7.77(\mathrm{~s}, 1 \mathrm{H}) ; 6.82(\mathrm{~s}, 1 \mathrm{H}) ; 3.33(\mathrm{~m}, 4 \mathrm{H}) ; 2.86(\mathrm{~m}, 2 \mathrm{H}) ; 2.75(\mathrm{~m}, 2 \mathrm{H}) ; 2.44(\mathrm{~s}, 3 \mathrm{H})$; $1.97(\mathrm{~m}, 4 \mathrm{H})$.

NMR ${ }^{13} \mathbf{C}\left(300 \mathrm{MHz}, \mathrm{CDCl}_{3}\right) \square \mathrm{ppm}$ :

$184.3 ; 160.6 ; 152.3 ; 150.2 ; 148.2 ; 125.9 ; 119.4 ; 108.1 ; 106.2 ; 98.8 ; 92.4 ; 87.9$; $50.2 ; 49.8 ; 32.5 ; 27.3 ; 21.0 ; 20.1 ; 20.0$.

IR $\left(\mathrm{NaCl}, \mathrm{cm}^{-1}\right): 2937,2844,2170,1714,1657,1620,1586,1520,1358,1295,1154$, 760.

HRMS (FAB): $308.1295\left(\mathrm{C}_{19} \mathrm{H}_{18} \mathrm{O}_{3} \mathrm{~N}, \mathrm{M}+1\right.$; calc 308.1287).

UV $(\mathrm{EtOH}): \square_{\max }=464 \mathrm{~nm}$.

Fluorescence (potassium phosphate $\mathrm{pH} 7.0$ ): $512 \mathrm{~nm}, \square_{\mathrm{f}}=0.01$.

\section{Fluorescence Spectra of Selected Probes 1-7:}

Compounds 1-4 were excited at $340 \mathrm{~nm}$, while compounds 5-7 were excited at $440 \mathrm{~nm}$. Fluorescence emission spectra were recorded with $10 \square \mathrm{M}$ solutions $(<1 \%$ DMSO v/v) in $100 \mathrm{mM}$ potassium phosphate buffer ( $\mathrm{pH} 7.0)$.

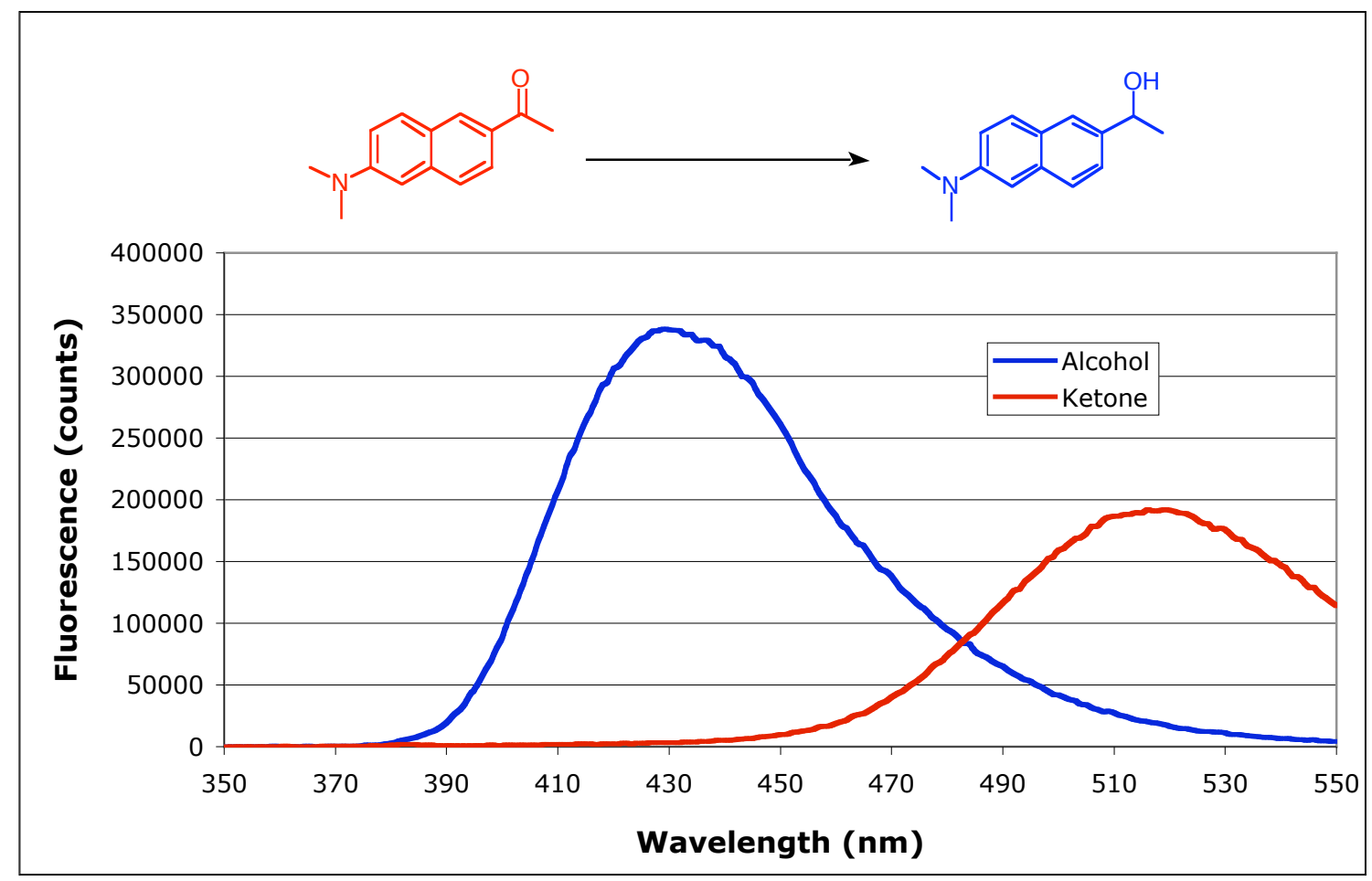



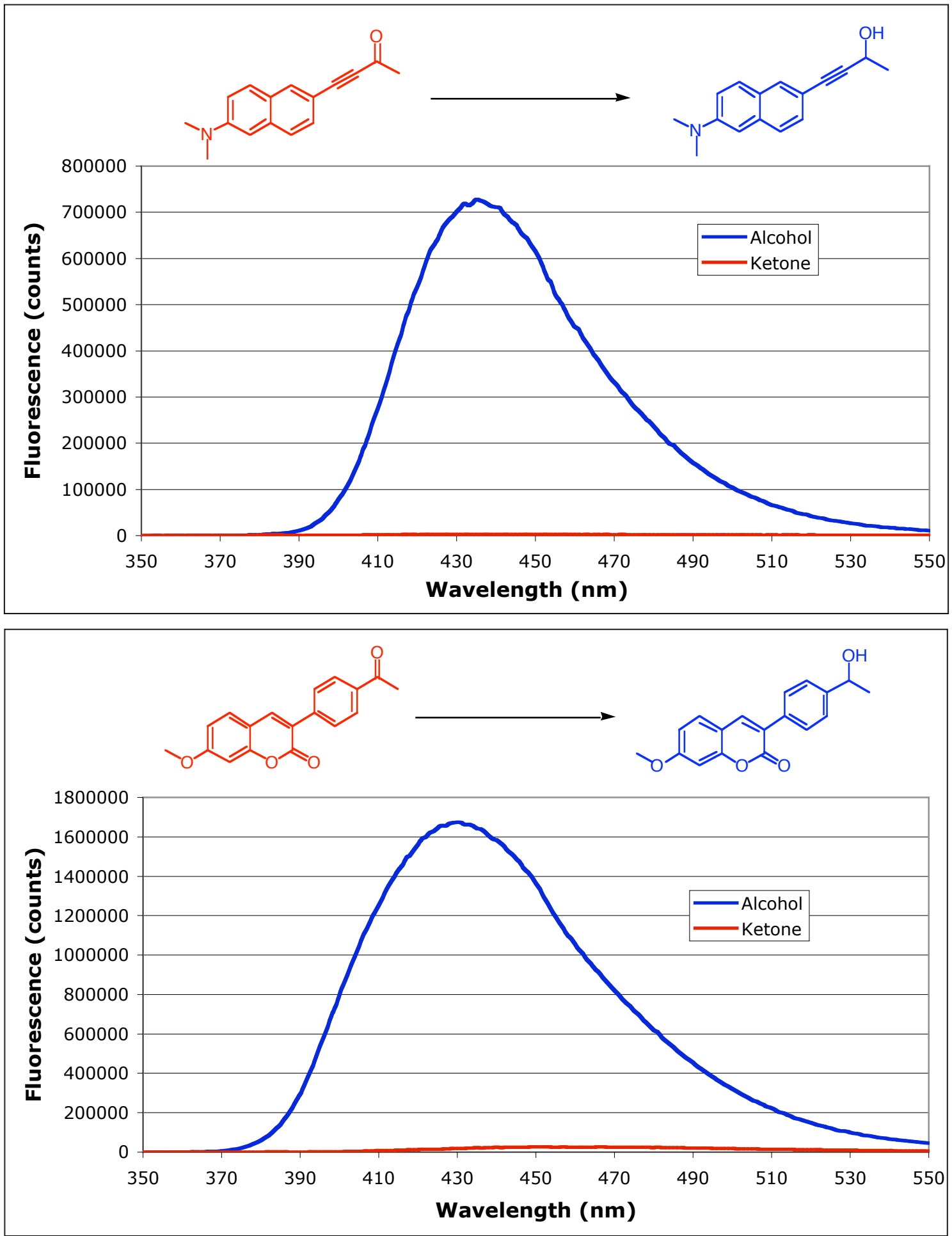

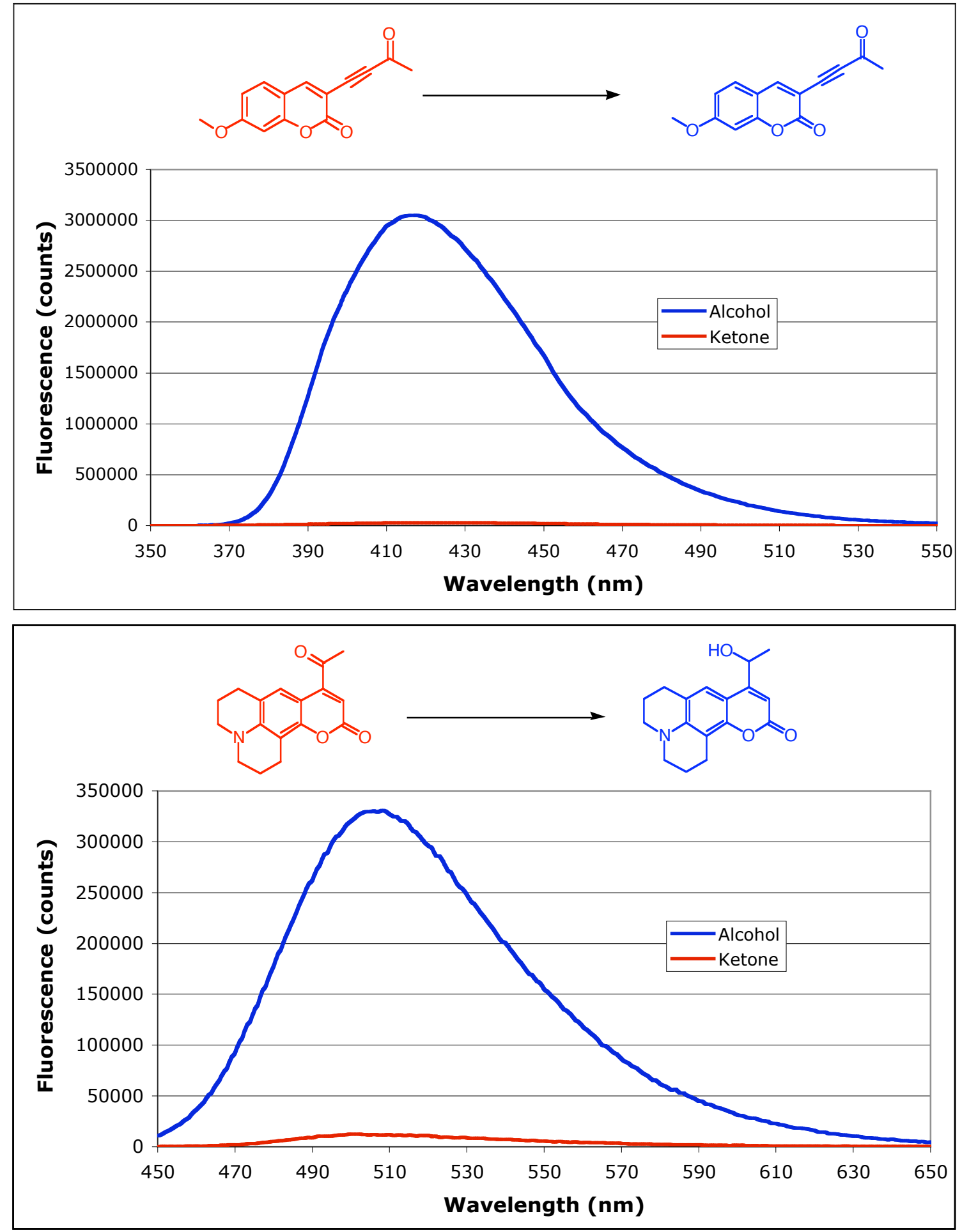

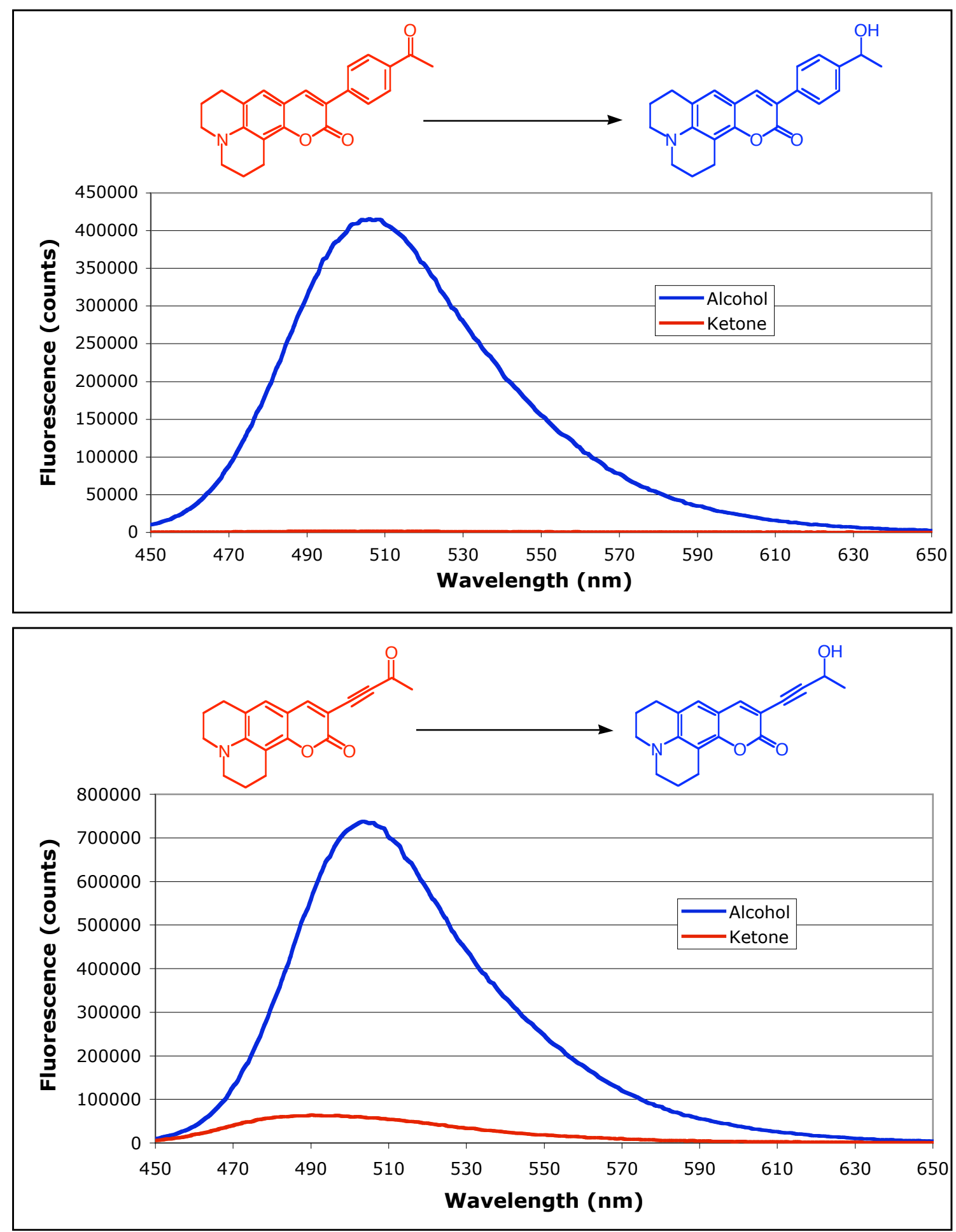
Photochemical Characterization of All Synthesized Compounds:

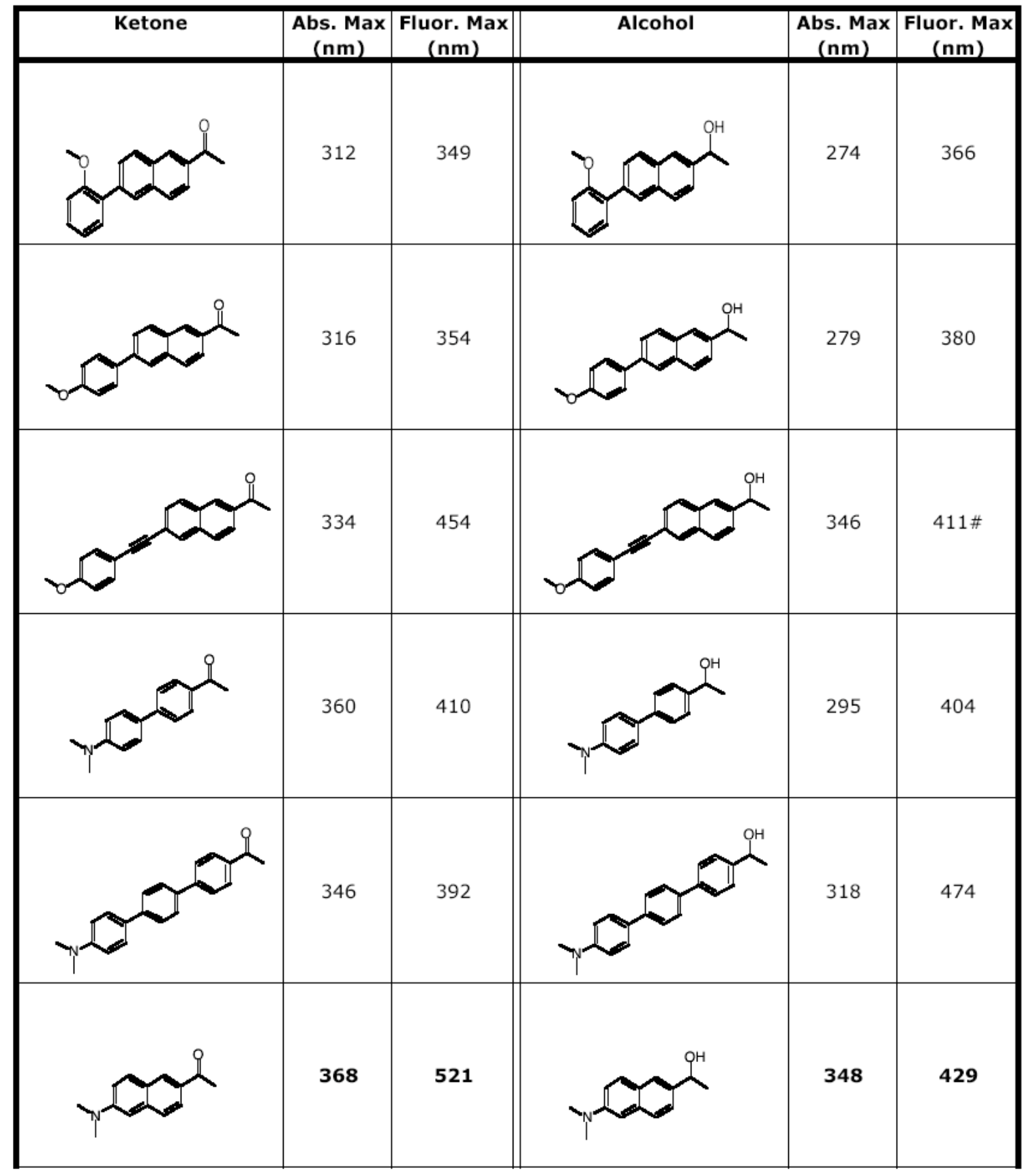




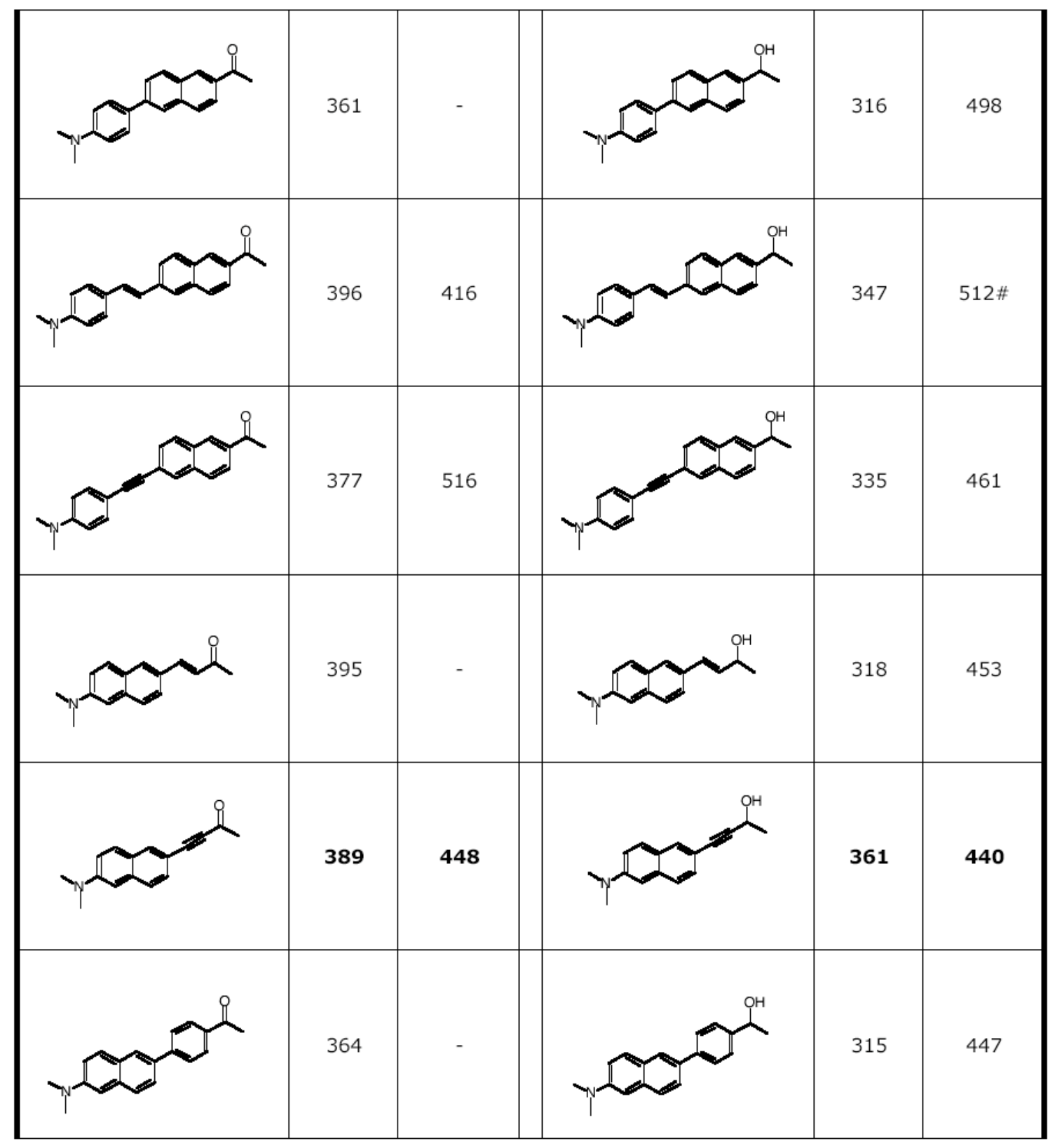




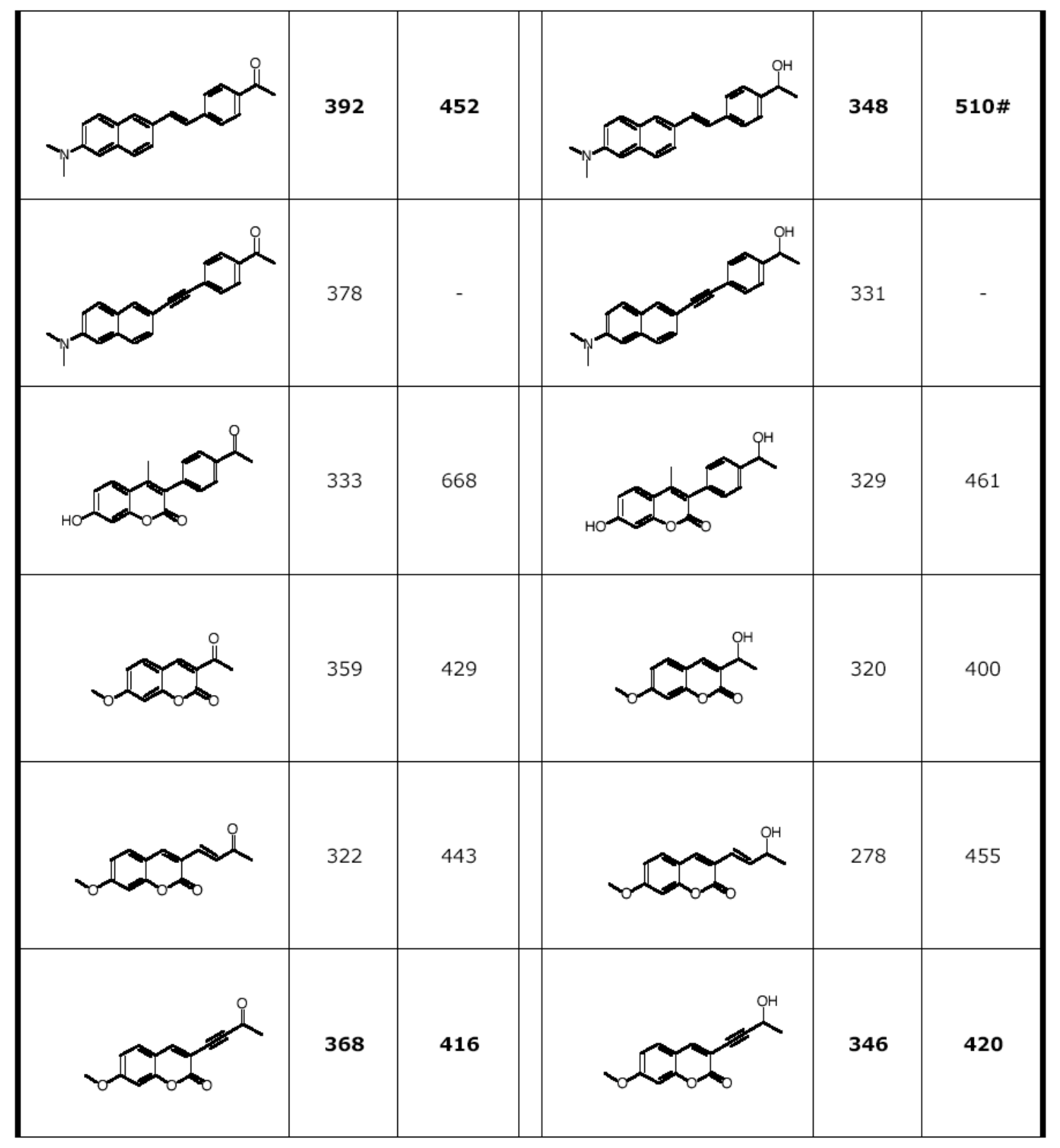




(158)




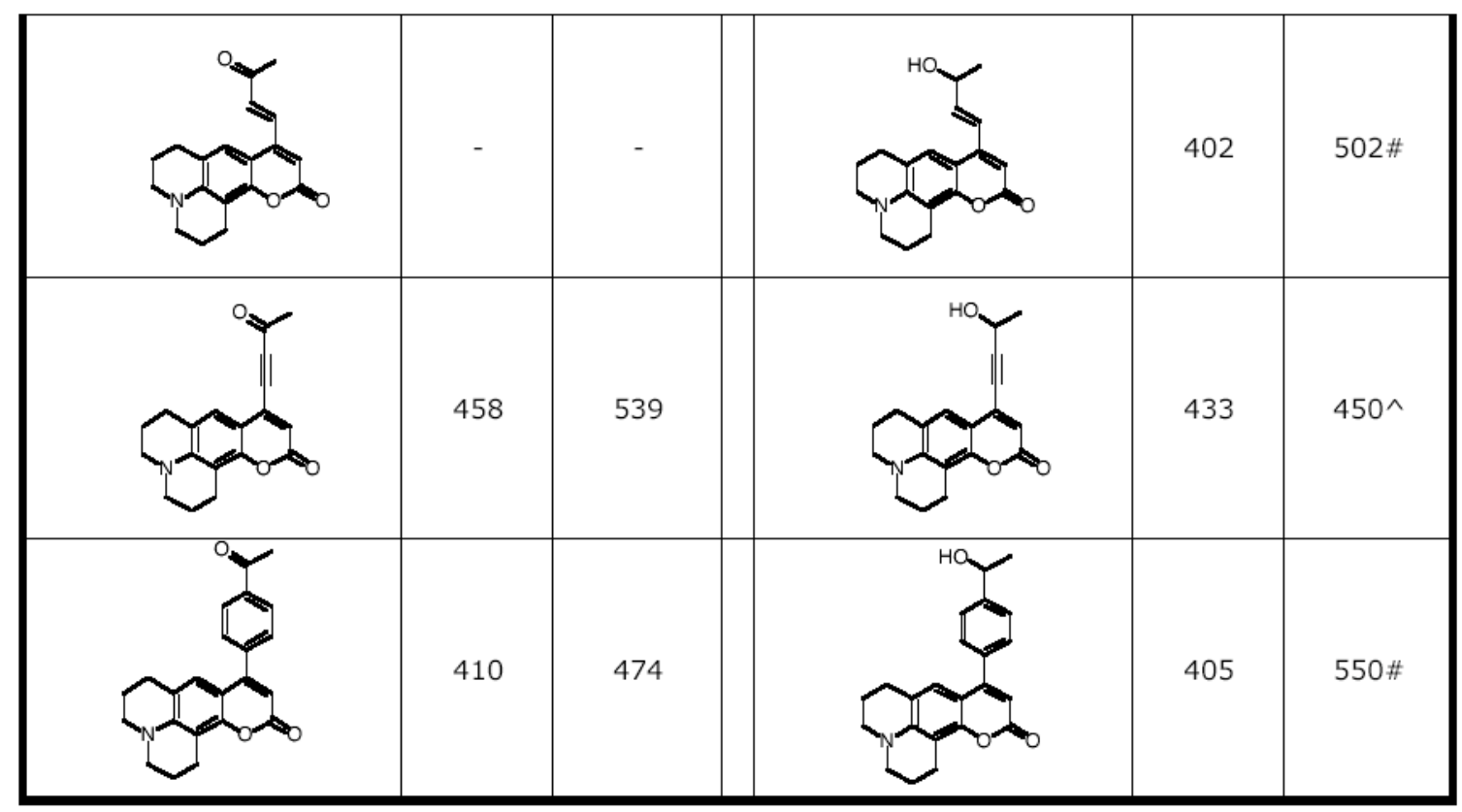

\# low quantum yield, $\wedge$ reactivity with cellular reductants, * no change in wavelength of emission 


\section{Protocols for Enzymatic Assays}

\section{Procedure for Enzymatic Screening of Selected Probes 1-7:}

Horse Liver alcohol dehydrogenase (Lot Number 51K7520), Thermoanaerobium brockii $\mathrm{NADP}^{+}$dependent alcohol dehydrogenase (Lot Number 033K4093), Pseudomonas testosteroni 3--hydroxysteroid dehydrogenase (Lot Number 053K8624), and Bacillus sphaericus 12 $\square$-hydroxysteroid dehydrogenase (Lot Number 70K16621) were purchased from Sigma. Yeast alcohol dehydrogenase (Lot Number 93122920), glycerol dehydrogenase (Lot Number 92110122), (D)-lactate dehydrogenase (Lot Number 92419236), (L)-lactate dehydrogenase (Lot Number 92801821), NAD ${ }^{+}, \mathrm{NADP}^{+}$, $\mathrm{NADH}$, and NADPH were purchased from Roche. Enzyme activity was confirmed by compliance to supplier's quality control assays prior to usage. Rat and human 3 $\square$ hydroxysteroid dehydrogenases were provided by Professor Trevor Penning (University of Pennsylvania School of Medicine) and human amyloid- $\square$ peptide binding alcohol dehydrogenase was supplied by Professor Shi Du Yan (Columbia University School for Physicians and Surgeons).

Enzymatic assays were performed in triplicate on selected fluorogenic substrates according to the following protocol. To each well of a FALCON 96-well black flat bottom plate was added (1) $40 \square \mathrm{L}$ of $500 \mathrm{mM}$ potassium phosphate buffer $\mathrm{pH} 7.0$, (2) $113 \square \mathrm{L}$ of double deionized water, (3) $25 \square \mathrm{L}$ of $2 \mathrm{mM}$ NADH (except for Pseudomonas

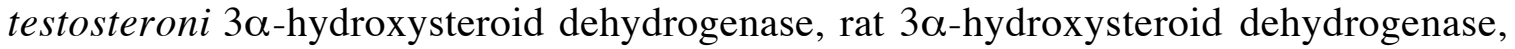
and Thermoanaerobium brockii $\mathrm{NADP}^{+}$dependent alcohol dehydrogenase, in which cases $2 \mathrm{mM}$ of NADPH was used), (4) $2 \square \mathrm{L}$ of a 3-5 mM solution of substrate in DMSO, and (5) $20 \square \mathrm{L}$ of a 40-50 $\square \mathrm{g} / \mathrm{mL}$ solution of enzyme. Reaction volumes were mixed thoroughly after addition of cofactor, substrate, and enzyme and allowed to react 12 hours at $25^{\circ} \mathrm{C}$. Scanning of the 96-well plate was performed by the MicroMax 384 connected to a Jobin Yvon Fluorolog through F-3000 fiber optic cables.

\section{Determination of Kinetic Parameters for AKR1C3}

Fluorogenic substrate $\mathbf{5}$ reduction was monitored on a Hitachi F-4500 fluorimeter in Starna quartz cuvettes fluorometrically in $1 \mathrm{~mL}$ systems containing $100 \mathrm{mM}$ potassium phosphate $\mathrm{pH} 6.0$ containing excess of NADPH cofactor $(250 \square \mathrm{M})$ and various amounts of the substrate $(0.1953-50 \square \mathrm{M})$ dissolved in $4 \%$ acetonitrile. Aqueous assay components were added first, followed by addition of $20 \square \mathrm{L}$ of acetonitrile as a cosolvent, and then addition of $20 \square \mathrm{L}$ of the substrate in acetonitrile (total acetonitrile in the assay did not exceed 4\%). Cuvettes were mixed thoroughly after addition of cofactor, cosolvent, and substrate. Reactions were initiated by the addition of $4 \square \mathrm{L}$ of dilute AKR1C3 (115 $\square \mathrm{g} / \mathrm{mL}$ ) and were corrected for nonenzymatic rates. All reactions were followed by monitoring the increase in fluorescence of the product alcohol for 5 minutes at $\square_{\mathrm{em}} 510$ $\mathrm{nm}$ with $\square_{\mathrm{ex}} 440 \mathrm{~nm}$ (Excitation and emission band pass slits both at $2.5 \mathrm{~nm}$, lamp $900 \mathrm{~V}$ ) at $37^{\circ} \mathrm{C}$. The initial velocities, expressed in units of nanomoles per minute, were calculated according to previously published procedures ${ }^{7}$ :

$$
\text { initial rate }=\left[\mathrm{n}_{\mathrm{st}} \times\left(\mathrm{F}_{\mathrm{t}}-\mathrm{F}_{0}\right) /\left(\mathrm{F}_{\mathrm{st}}\right)\right] / \mathrm{t}
$$


where $F_{t}$ and $F_{0}$ represent the fluorescence at time $t$ and $0, n_{s t}$ is the nanomoles of the product standard, and $\mathrm{F}_{\mathrm{st}}$ is the fluorescence resulting from $\mathrm{n}_{\mathrm{st}}$ of product. Kinetic constants were approximated using the GraFit (Erithacus Software, Surrey, UK) nonlinear regression analysis program to fit the untransformed data to a hyperbolic function as originally described ${ }^{9}$, yielding estimated values of $\mathrm{k}_{\mathrm{cat}}, \mathrm{K}_{\mathrm{m}}$, and their associated standard errors.

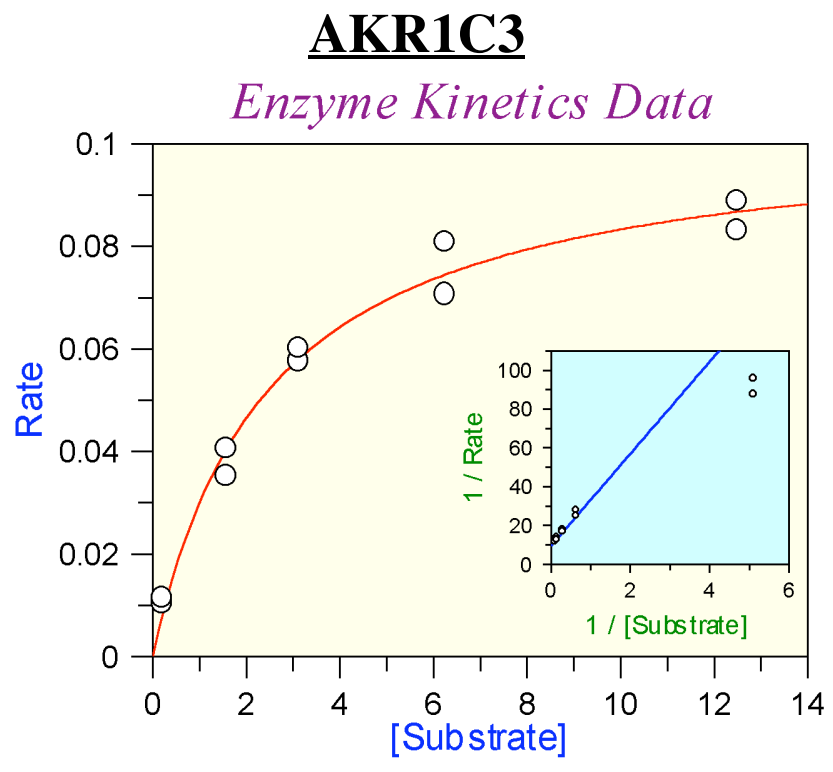

\begin{tabular}{lcc}
\hline Parameter & Value & Std. Error \\
\hline Vmax & 0.1039 & $0.0049 \mathrm{nmol} / \mathrm{min}$ \\
$\mathrm{Km}$ & 2.4637 & $0.3511 \mathrm{uM}$ \\
$\mathrm{kcat}$ & 8.244 & $0.389 \mathrm{~min}^{-1}$ \\
$\mathrm{kcat} / \mathrm{Km}$ & 335 & $\mathrm{~min}^{-1} / \mathrm{mM}^{-1}$ \\
Spec. activity & 0.226 & $0.011 \mathrm{umol} / \mathrm{min} / \mathrm{mg}$ \\
\hline
\end{tabular}

AKR1C3 kinetic data was also performed by HPLC separation of the fluorogenic substrate and its product alcohol and measurement of ketone to alcohol ratios. This data was found to correlate well with kinetic parameters determined fluorometrically ${ }^{10}$. 


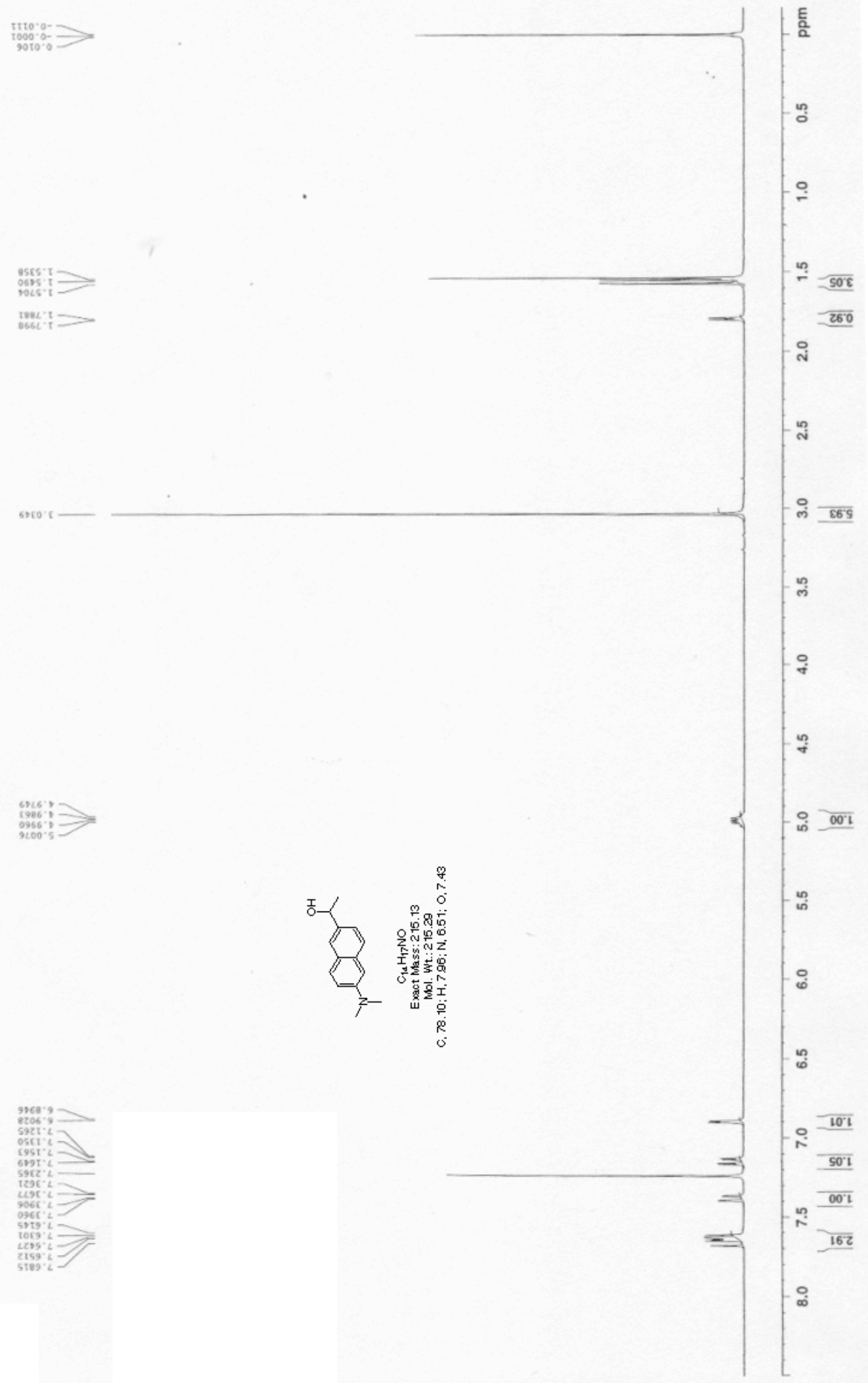




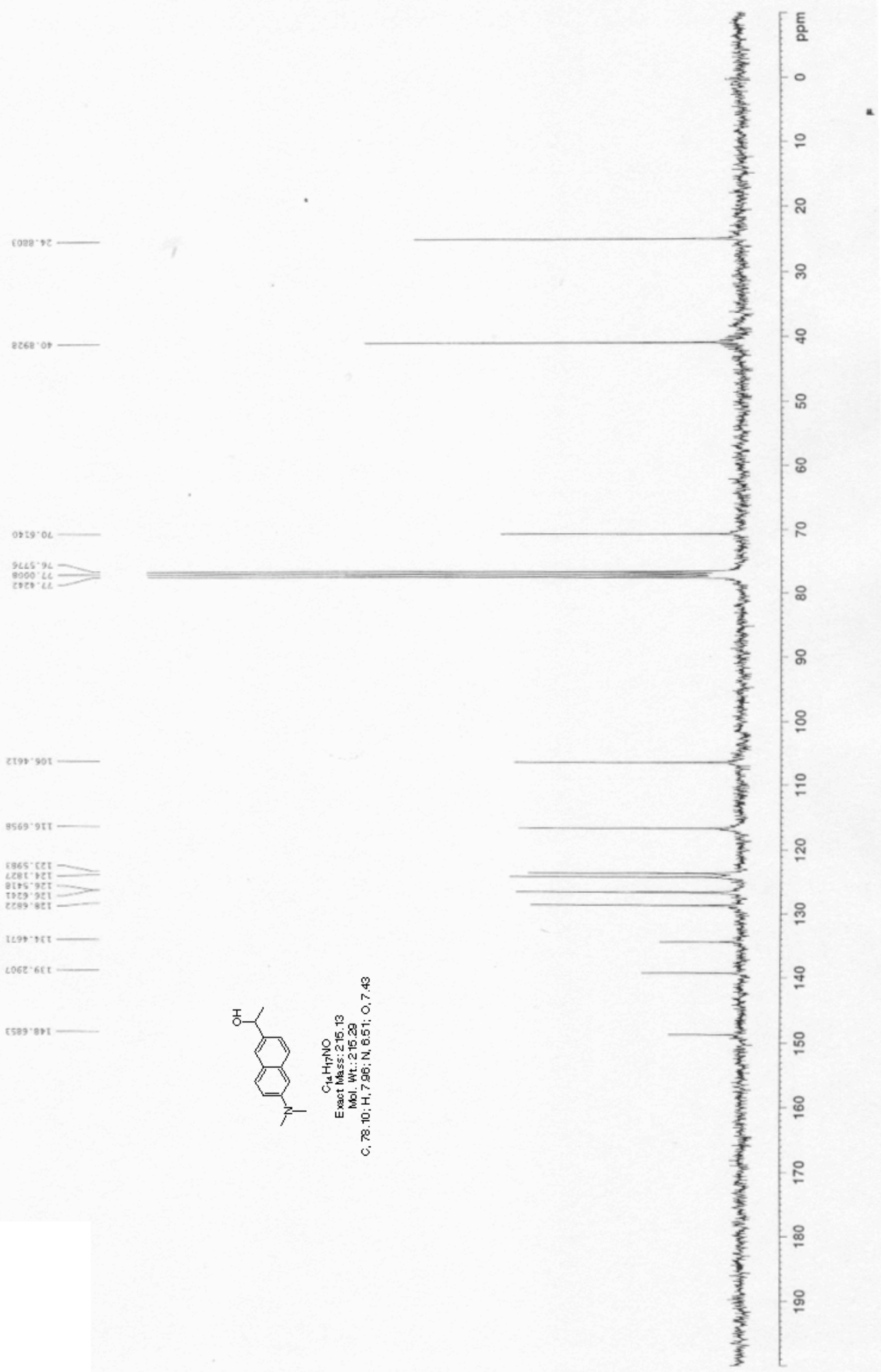




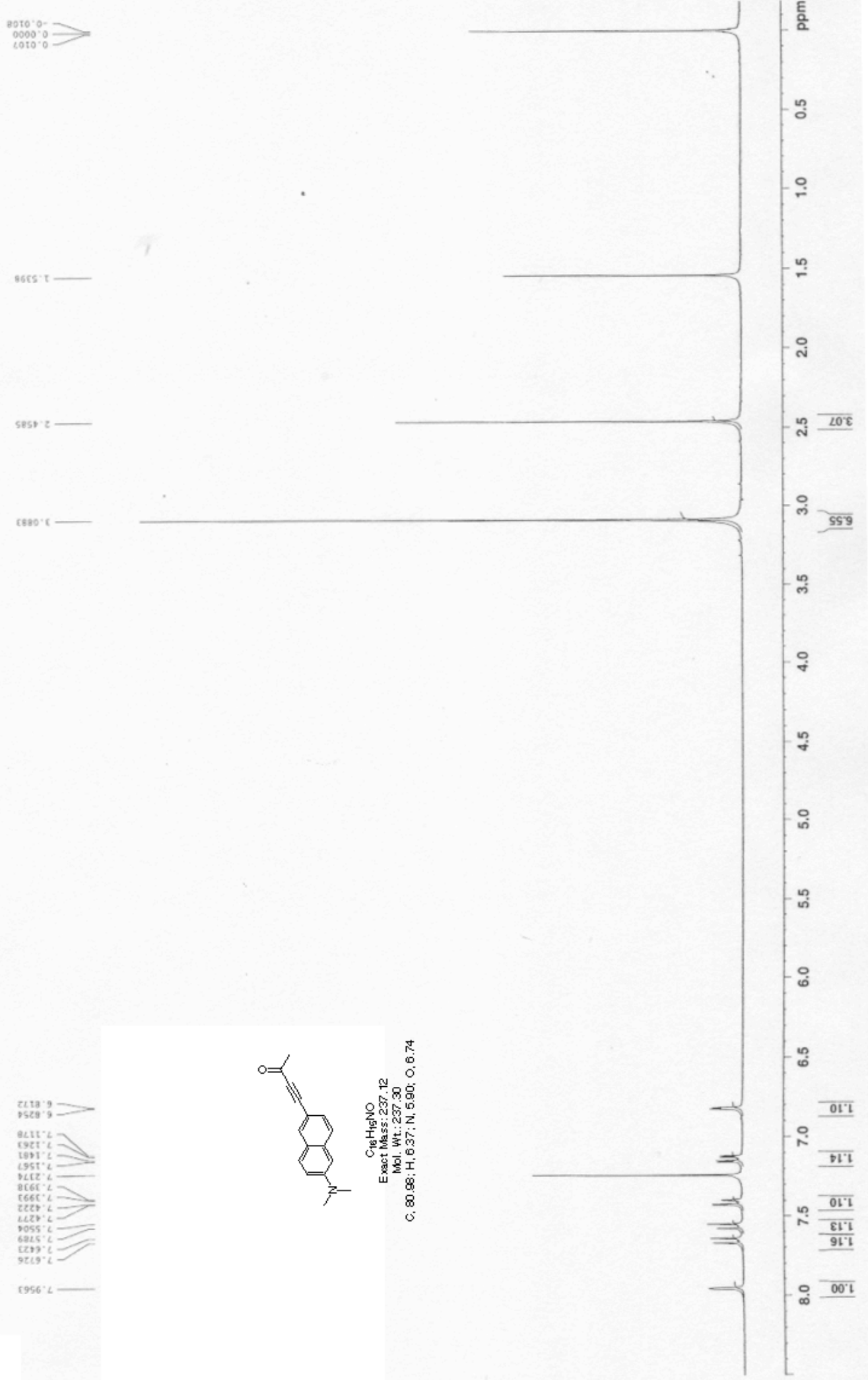

S23 

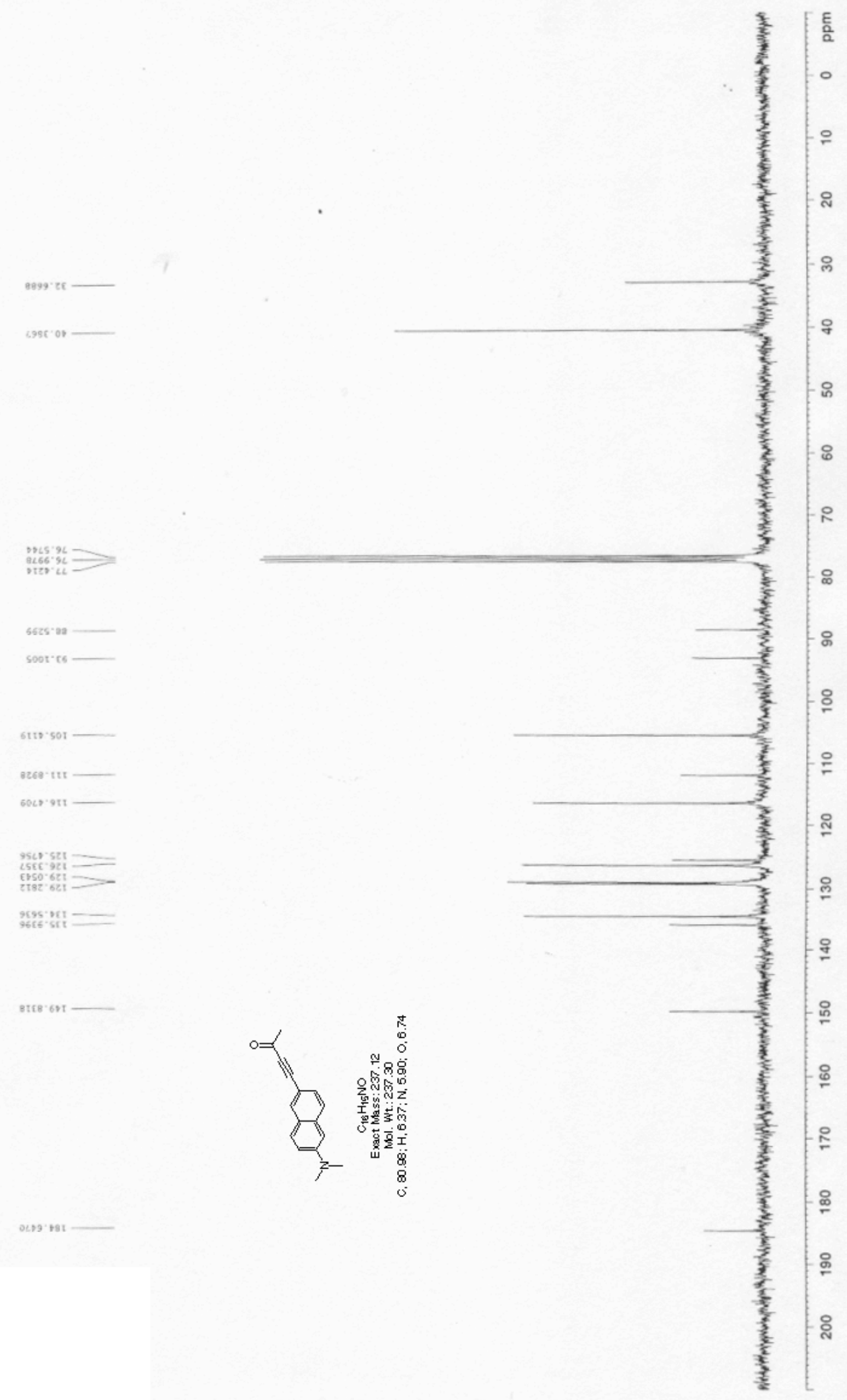


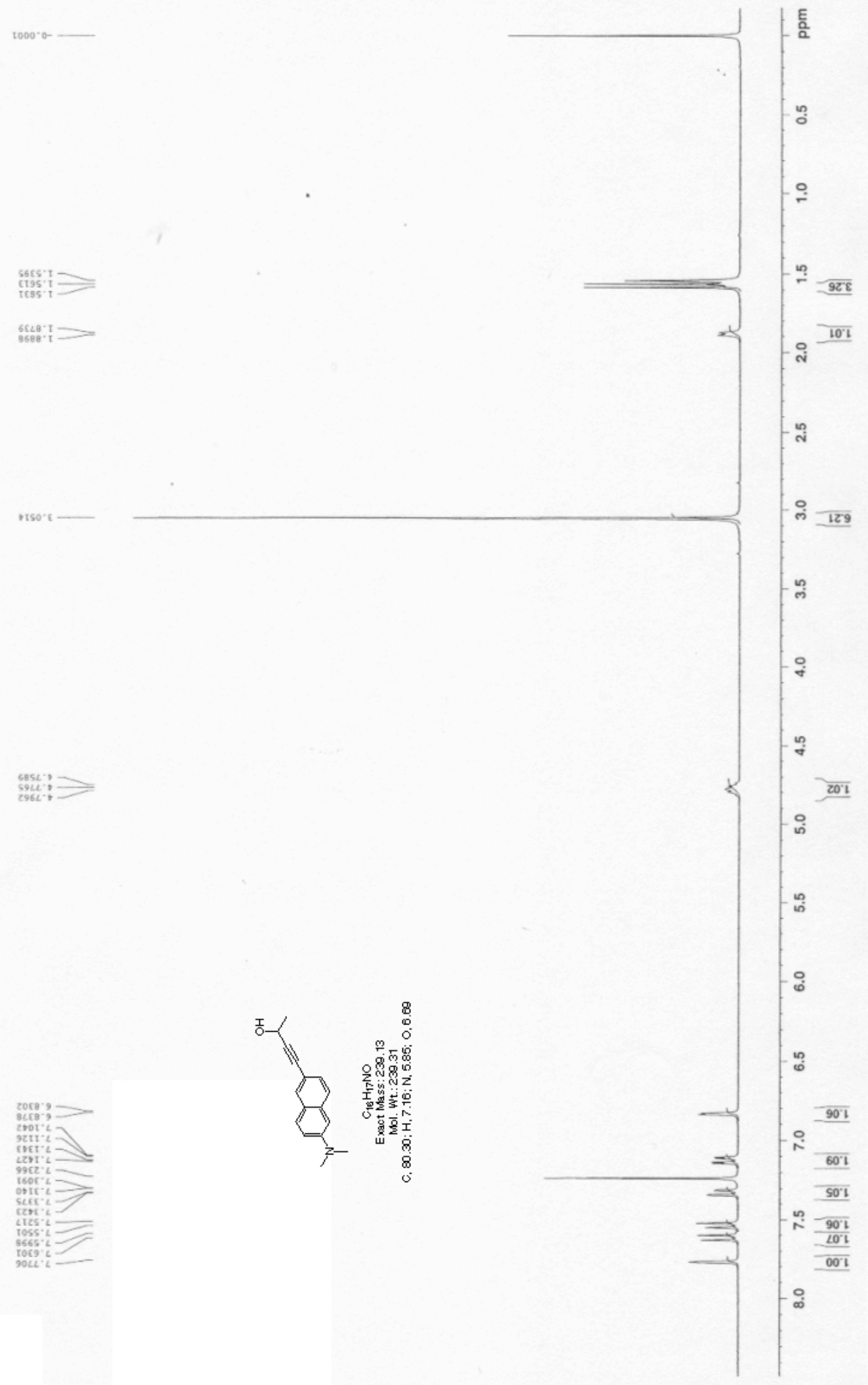




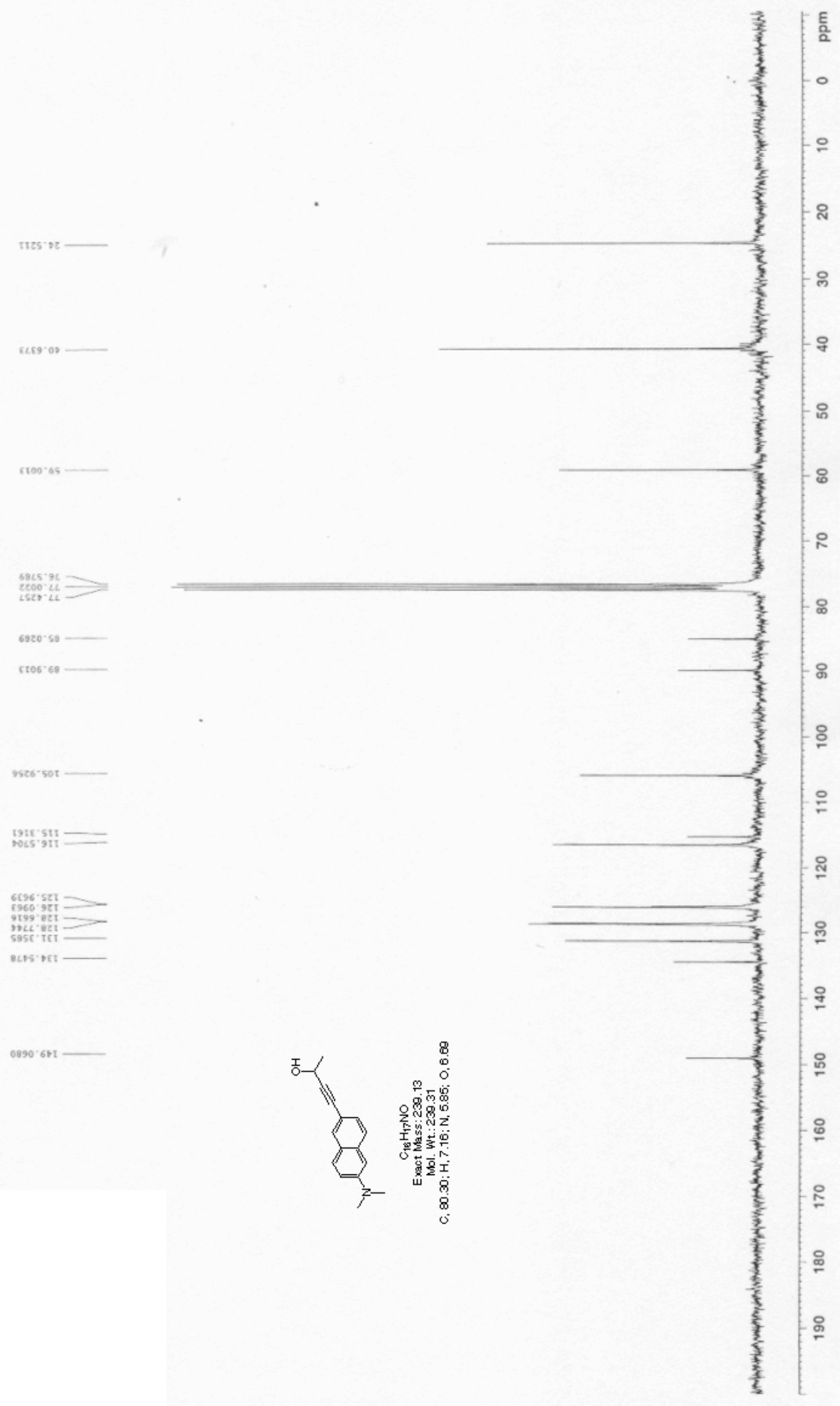




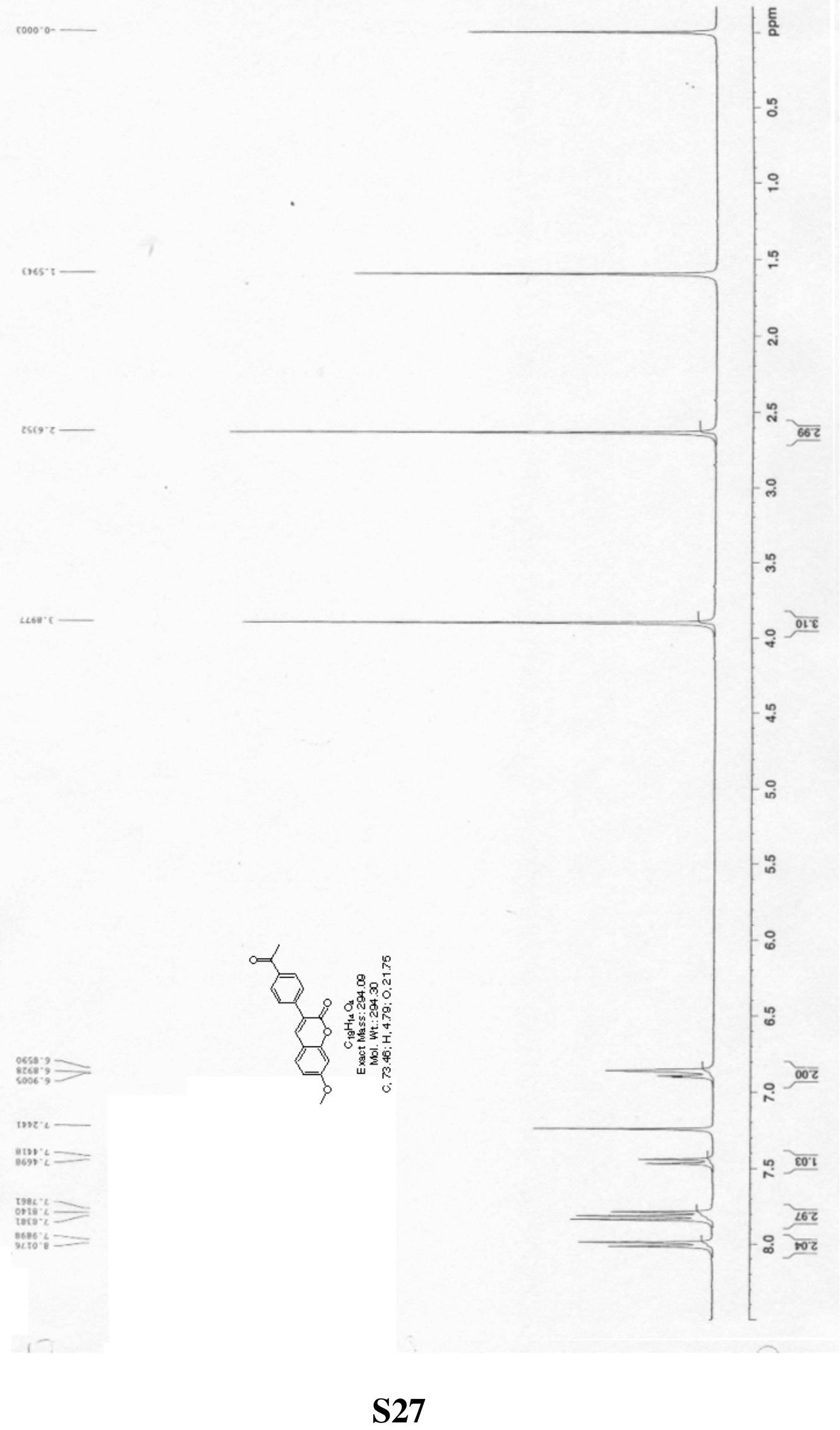




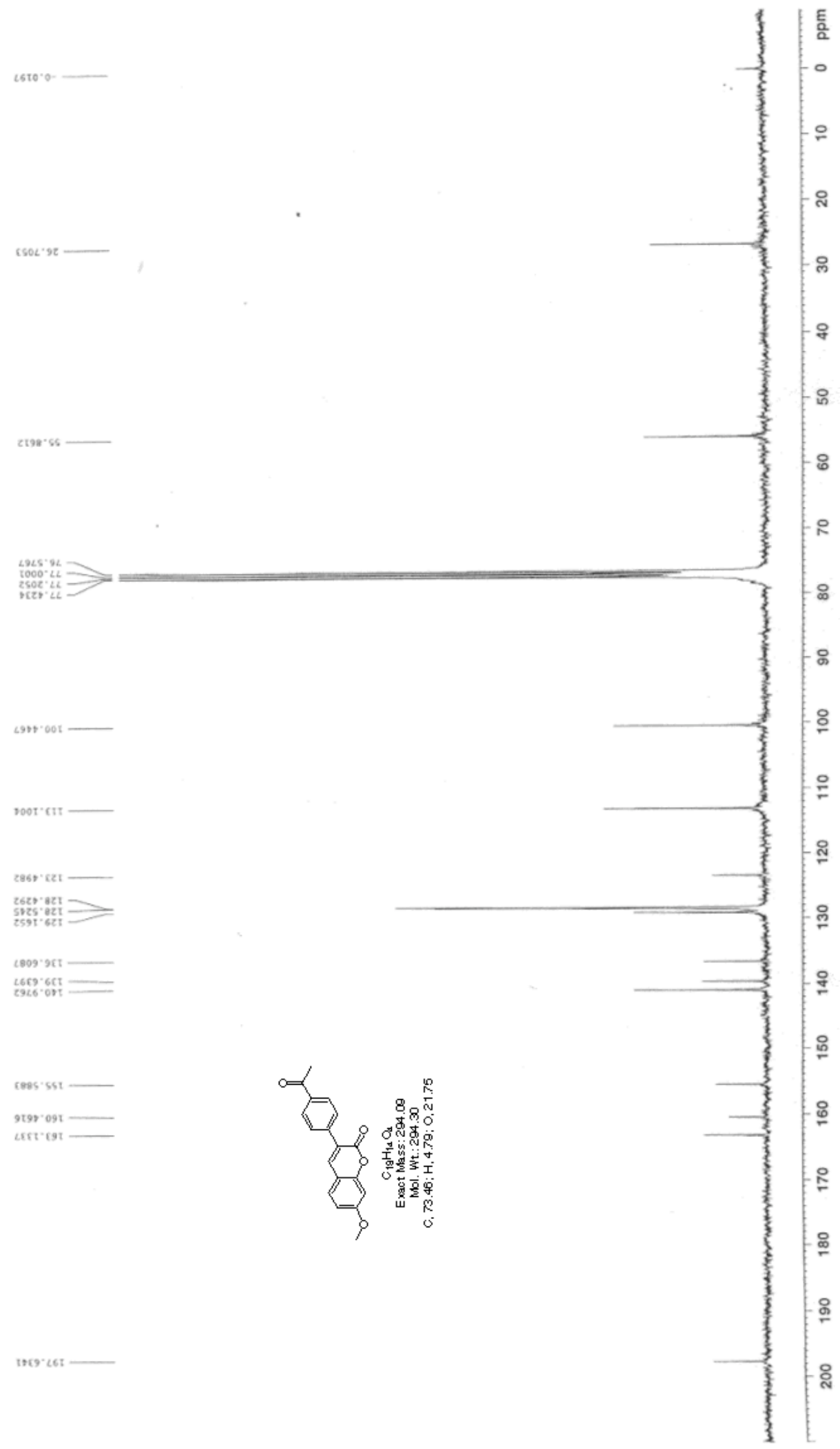




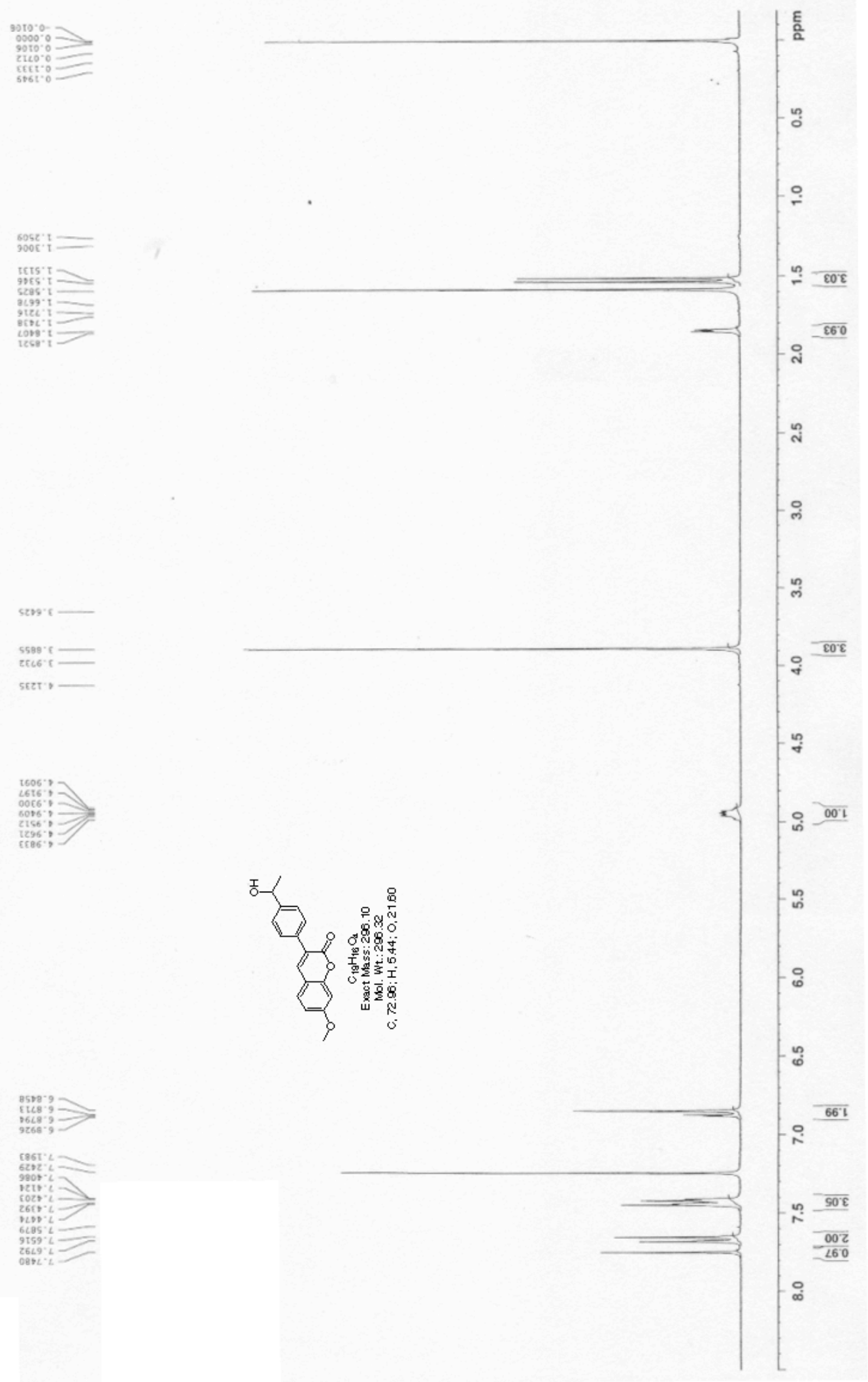




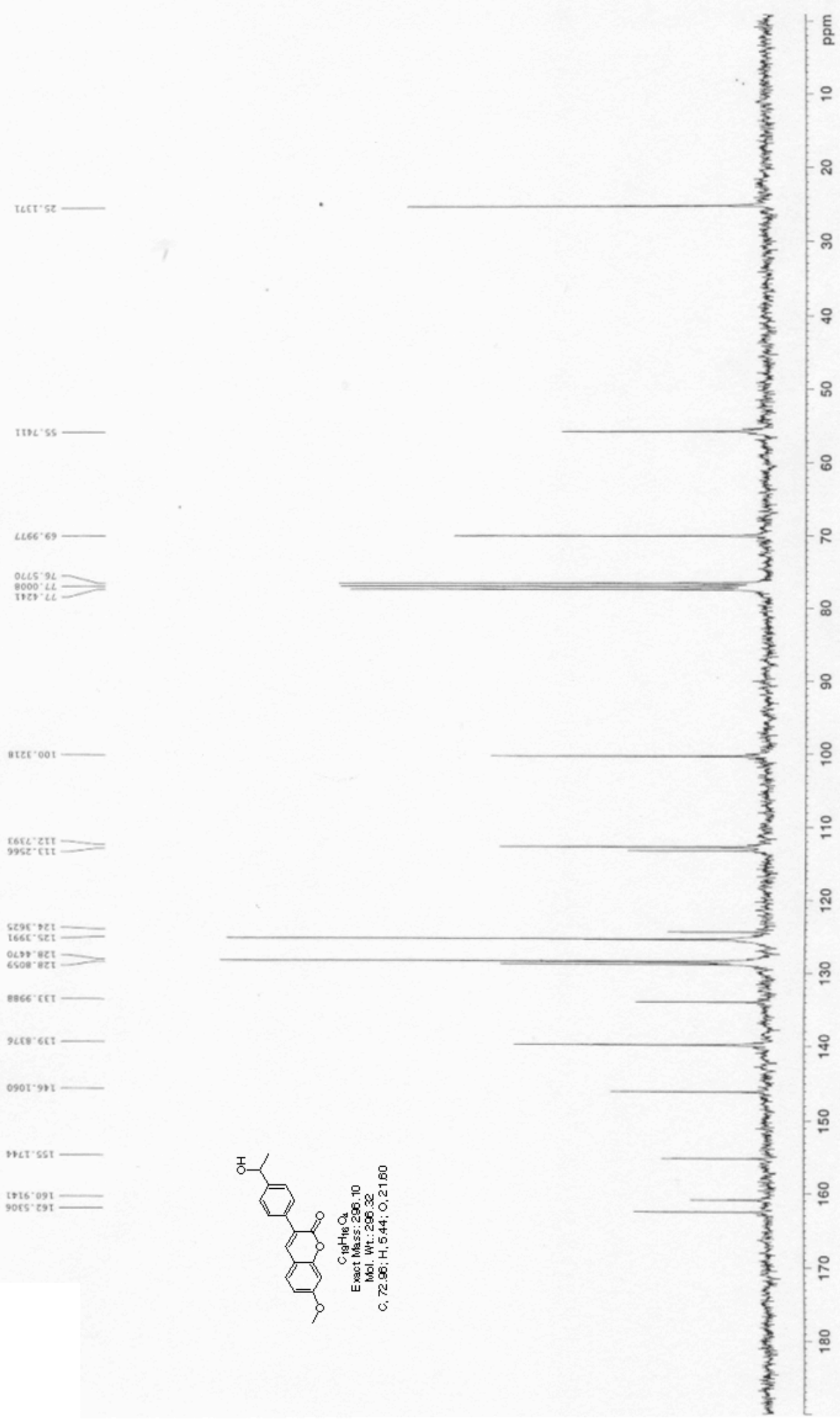




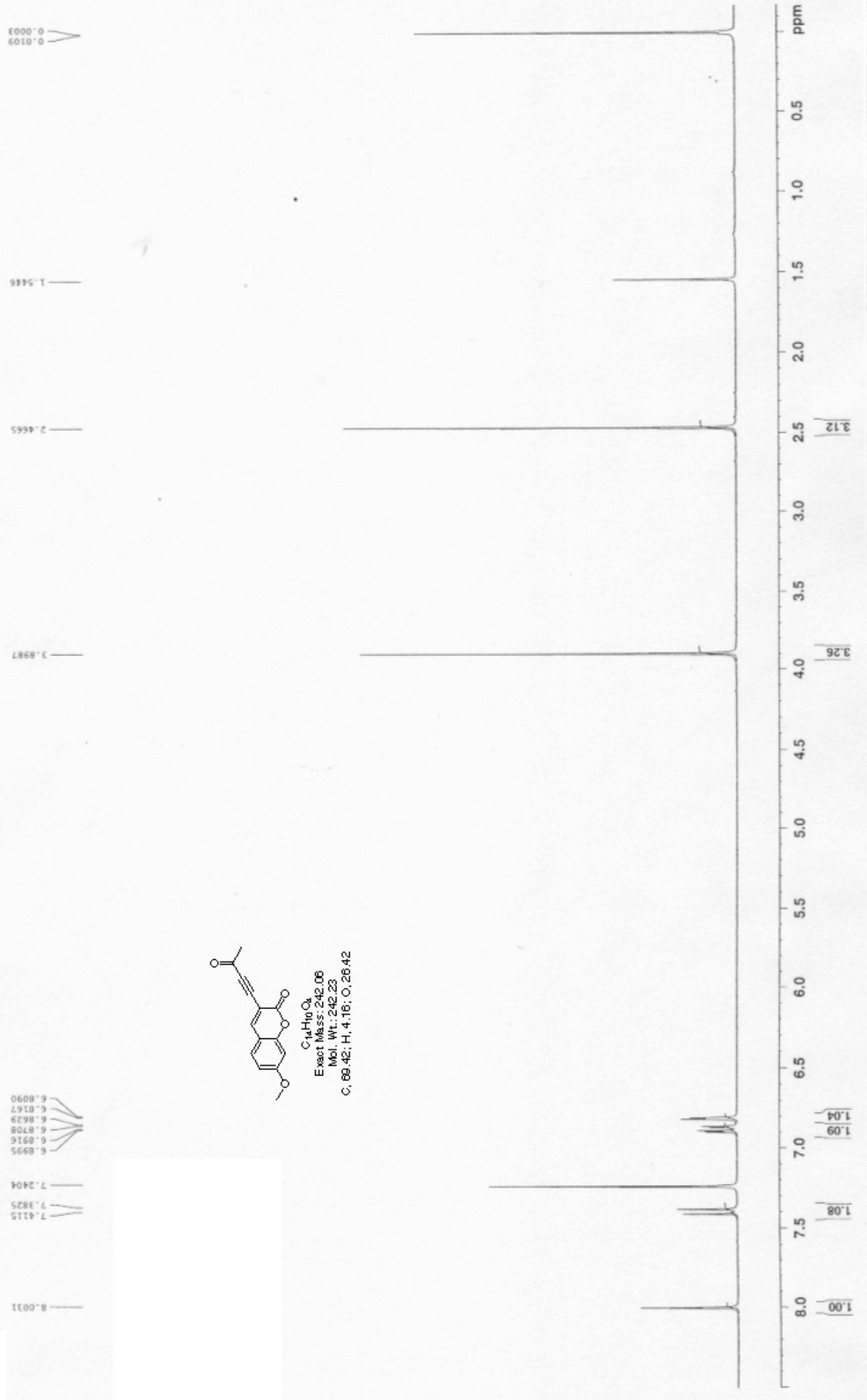

\section{S31}




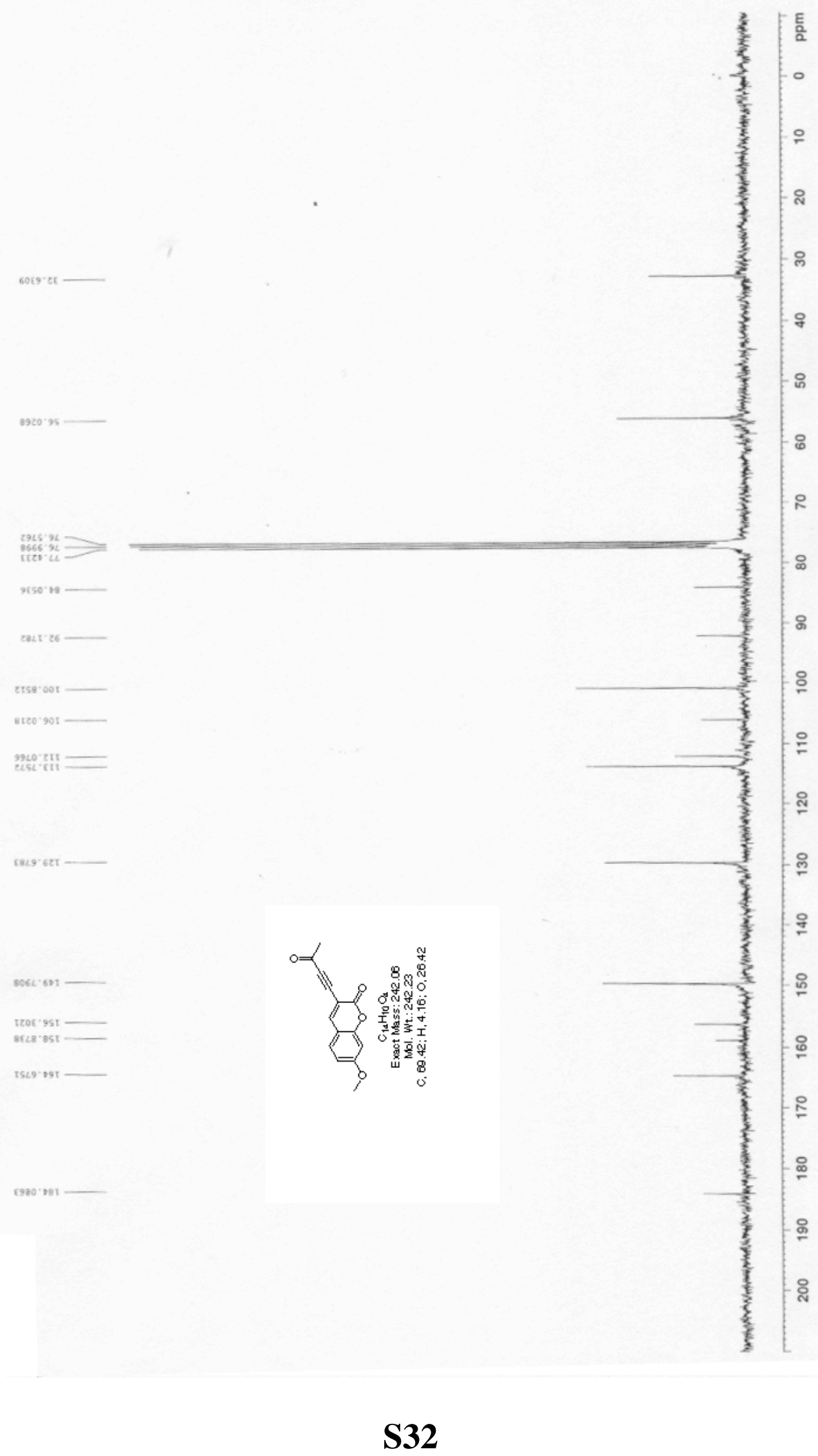



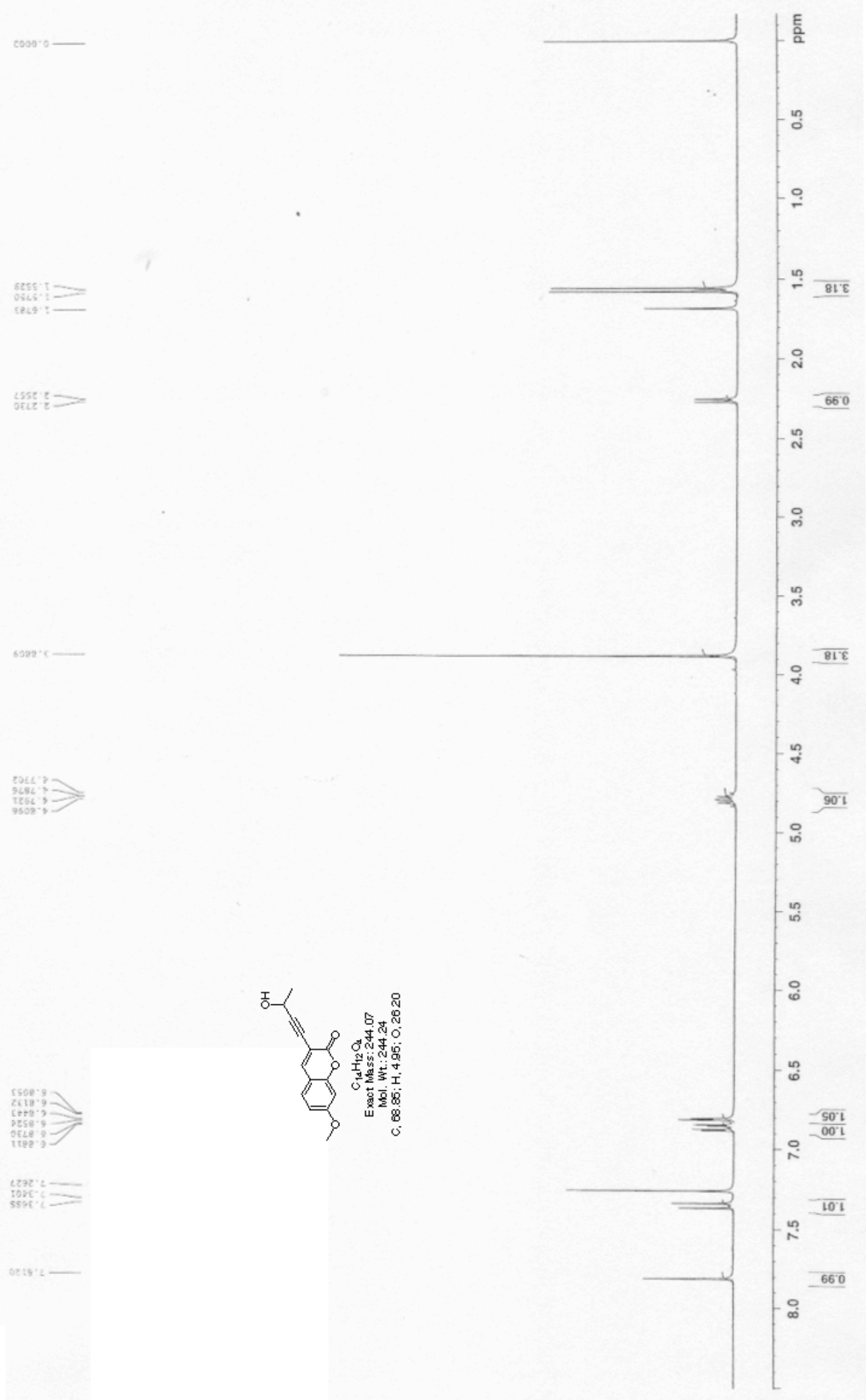

S33 


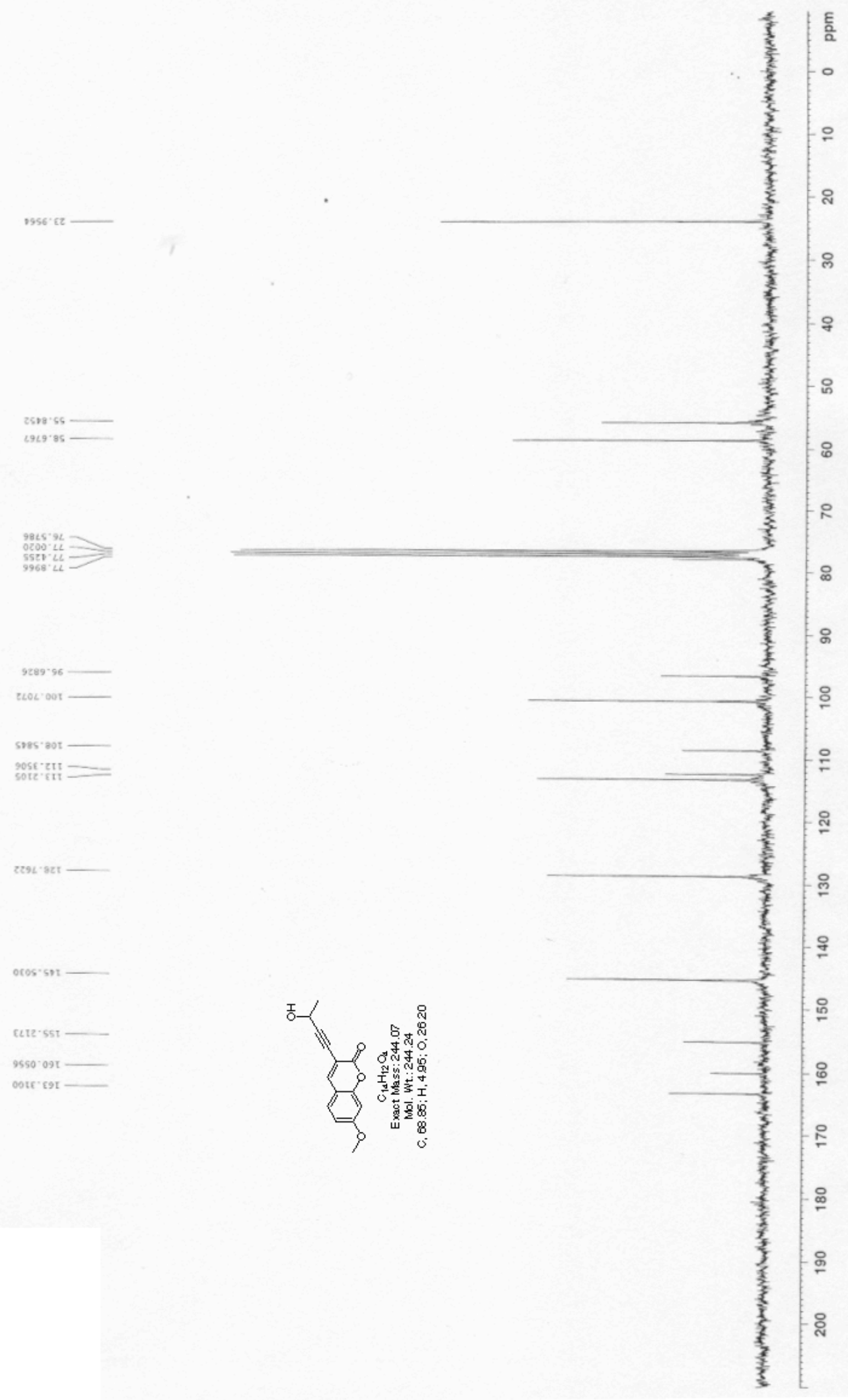




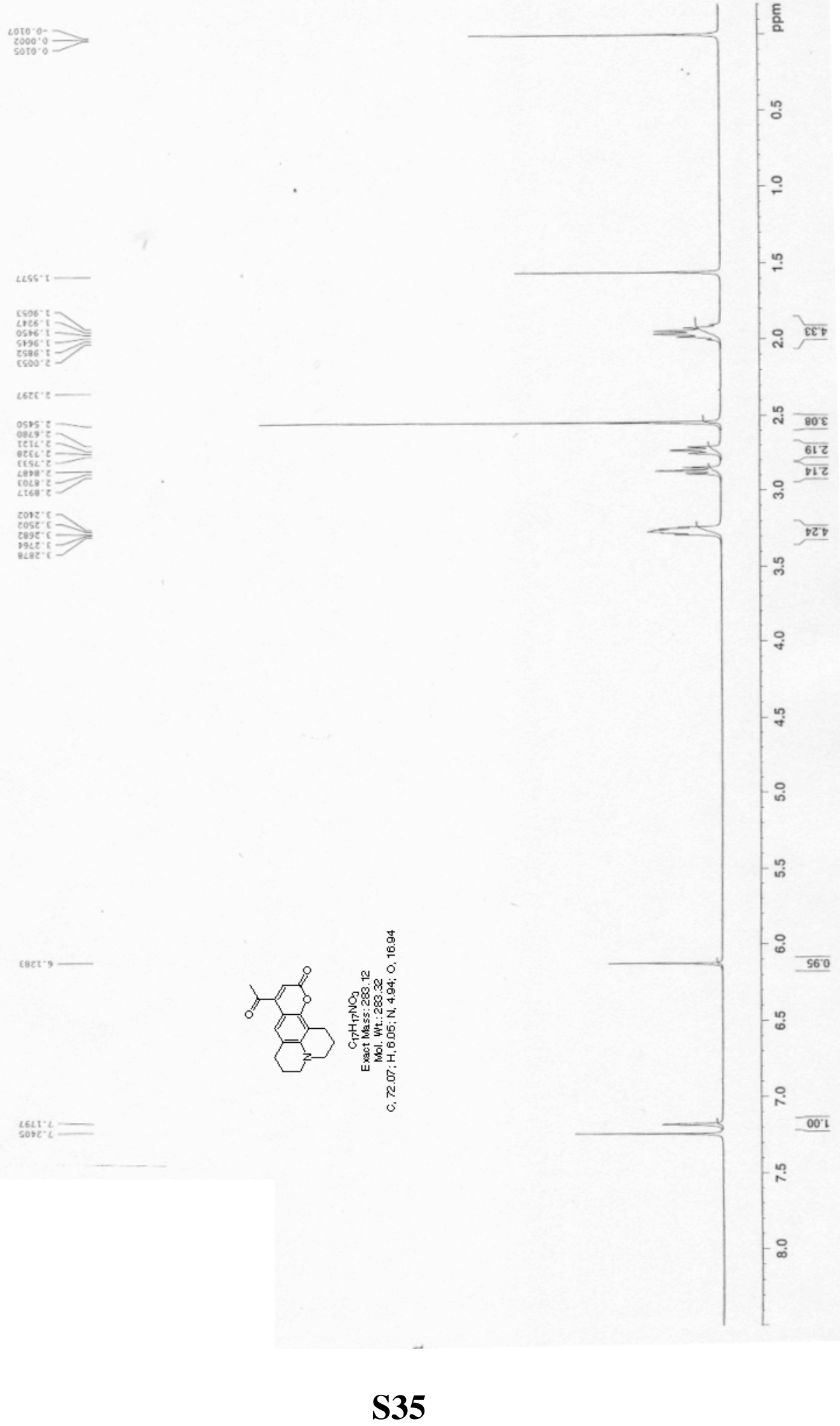




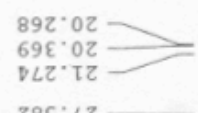

$285^{\circ} \mathrm{LZ}-$

$66 \varepsilon^{\circ} 60$

$8 \angle 8^{\circ} 60$

$666^{\circ} 9 L$
$\varepsilon 20^{\circ} L L$

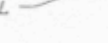

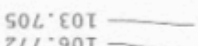
ZLL:90I

$2 \nabla L \cdot 8 \tau t$

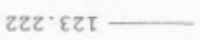

\begin{tabular}{l}
$\nabla 0 \mathrm{C}^{\circ} 90 \mathrm{~T}-$ \\
$85 L^{\circ}-05 \mathrm{~L}$ \\
\hline
\end{tabular} 8SL'0St

๕80. $29 \mathrm{I}$

$68 \varepsilon \cdot 002-$

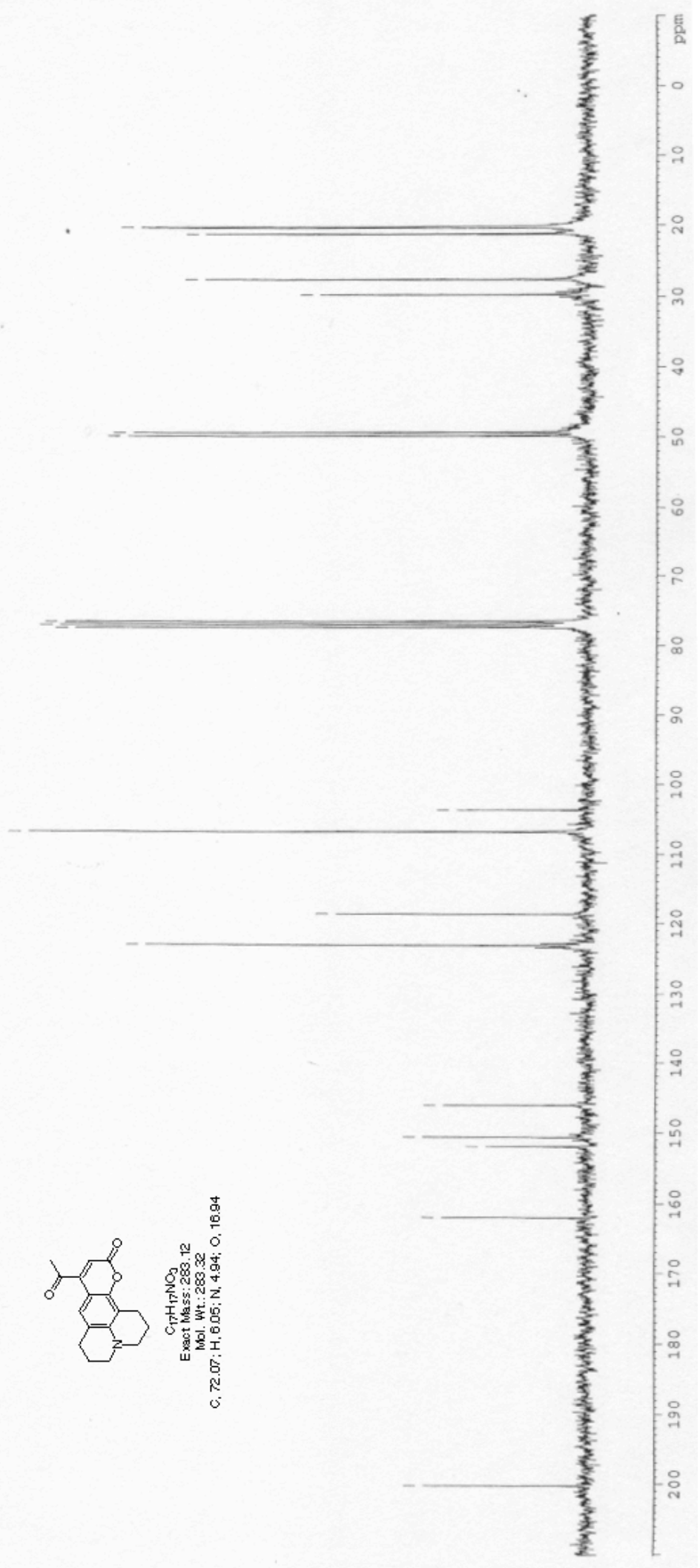

S36 


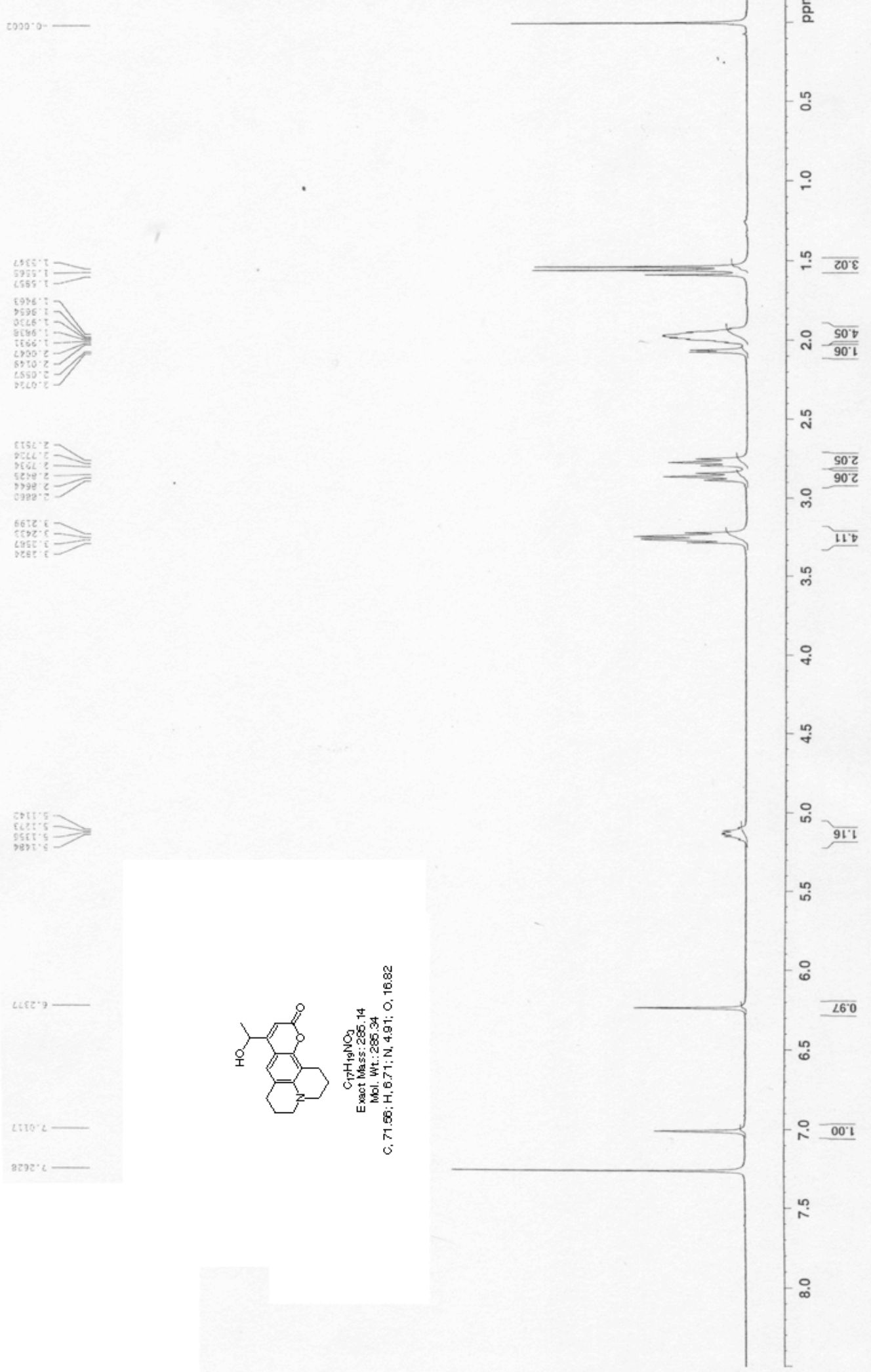




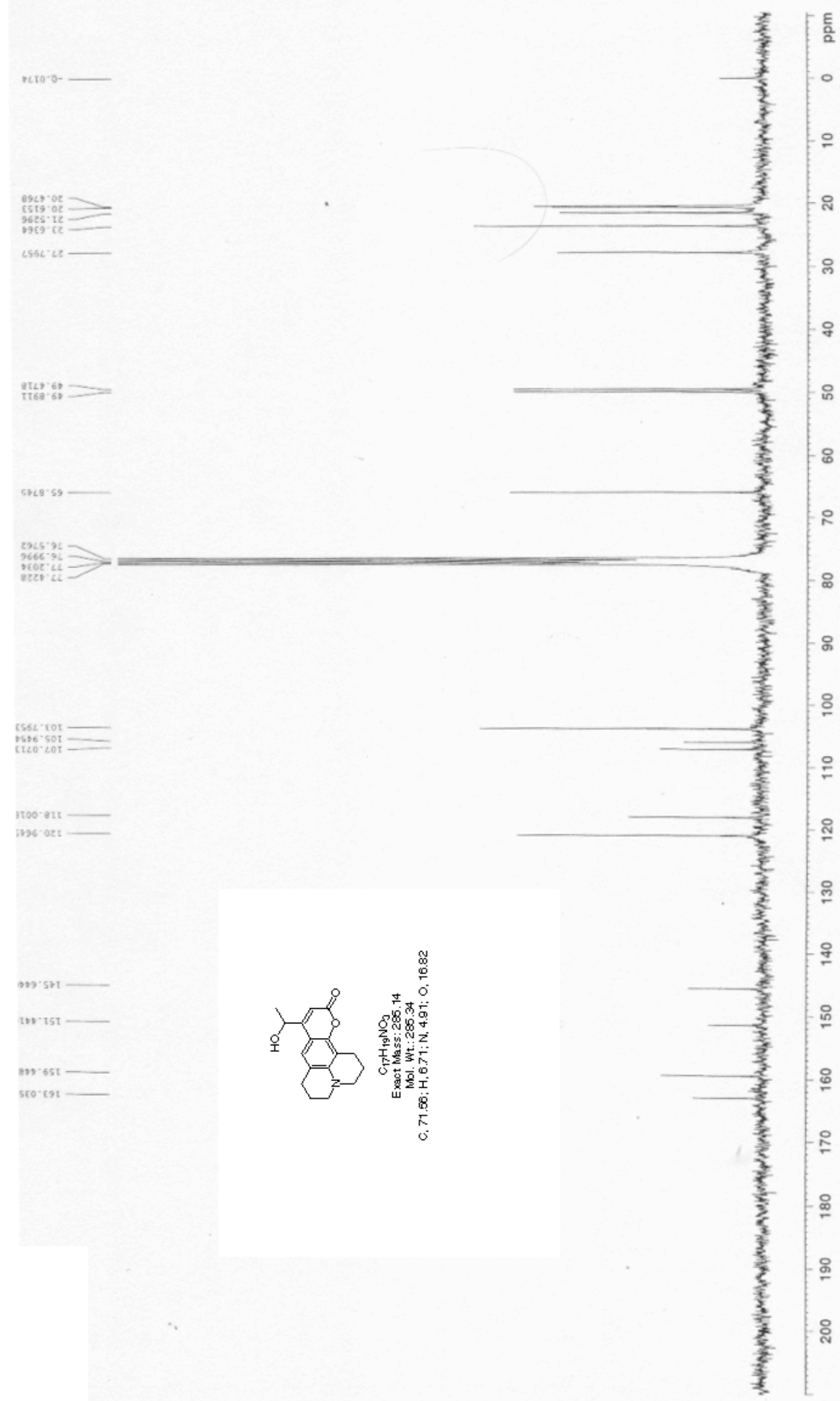




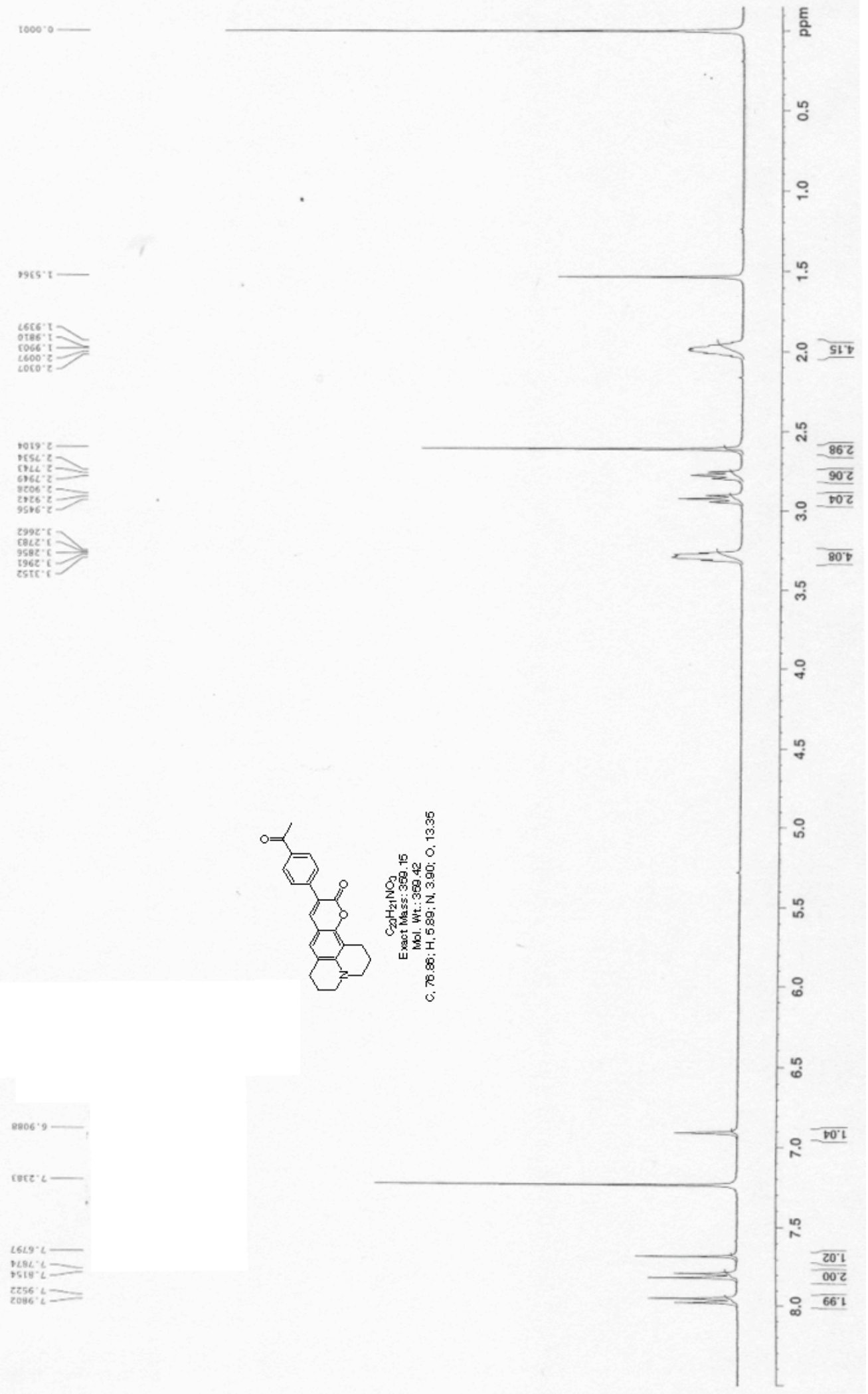



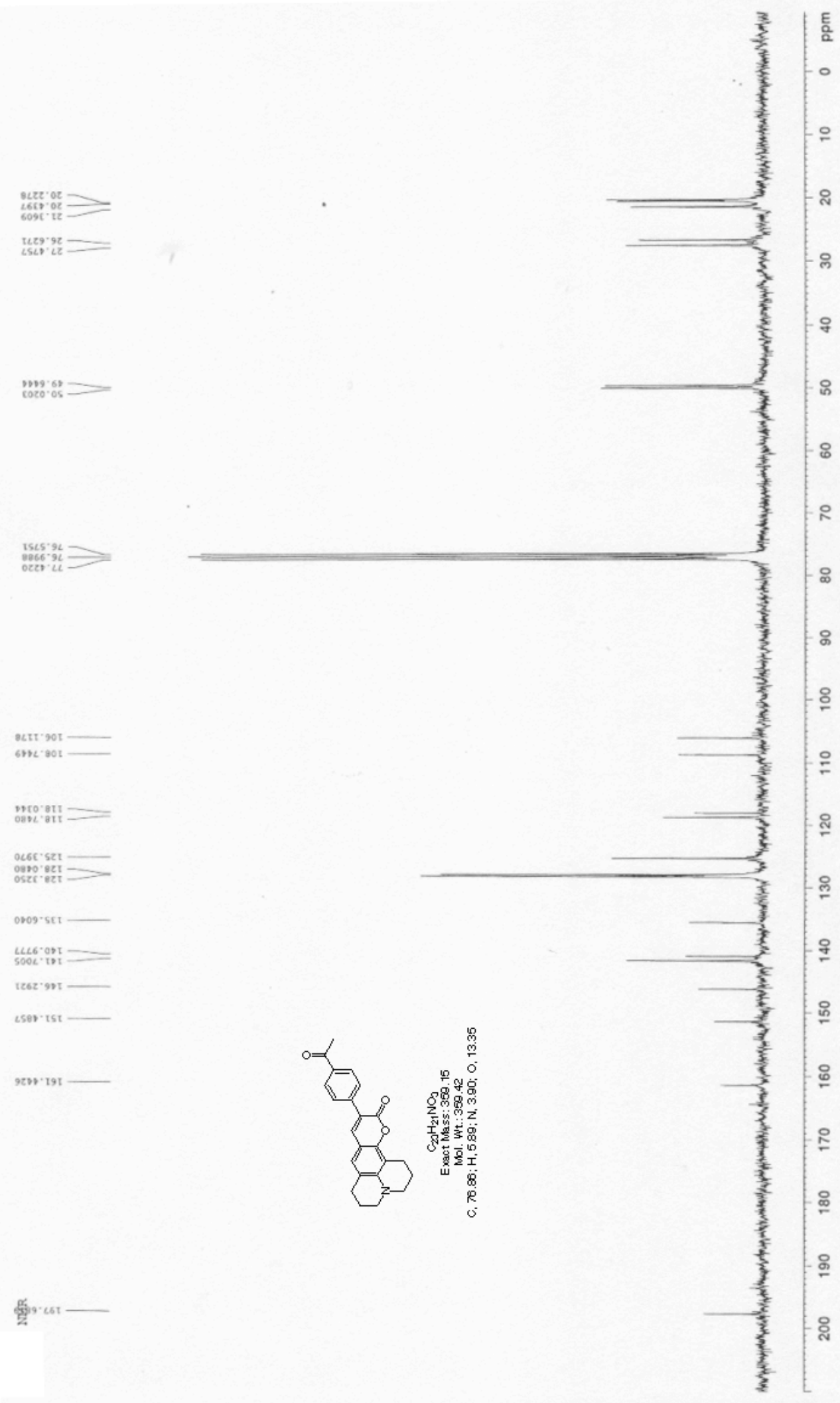


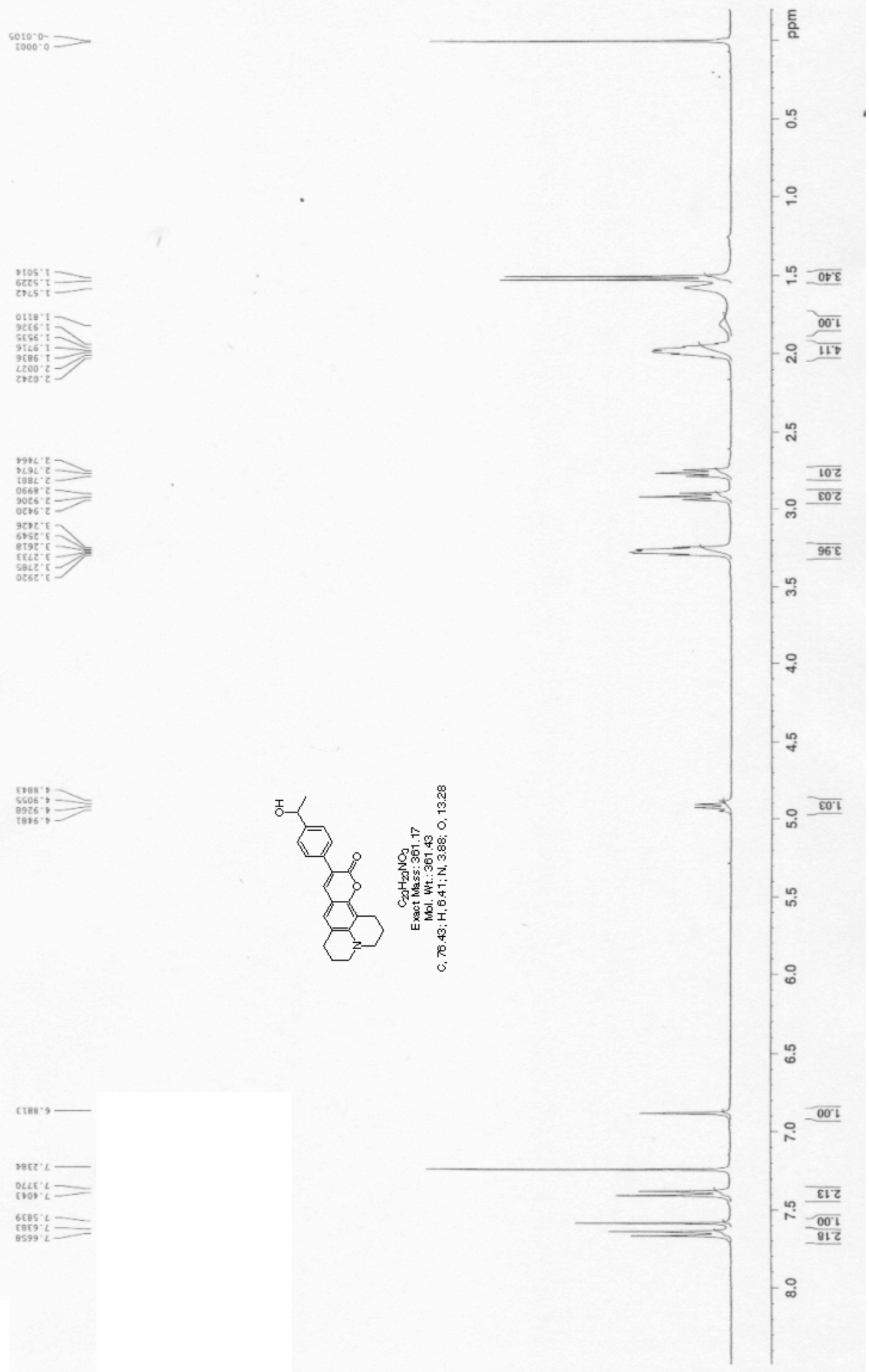




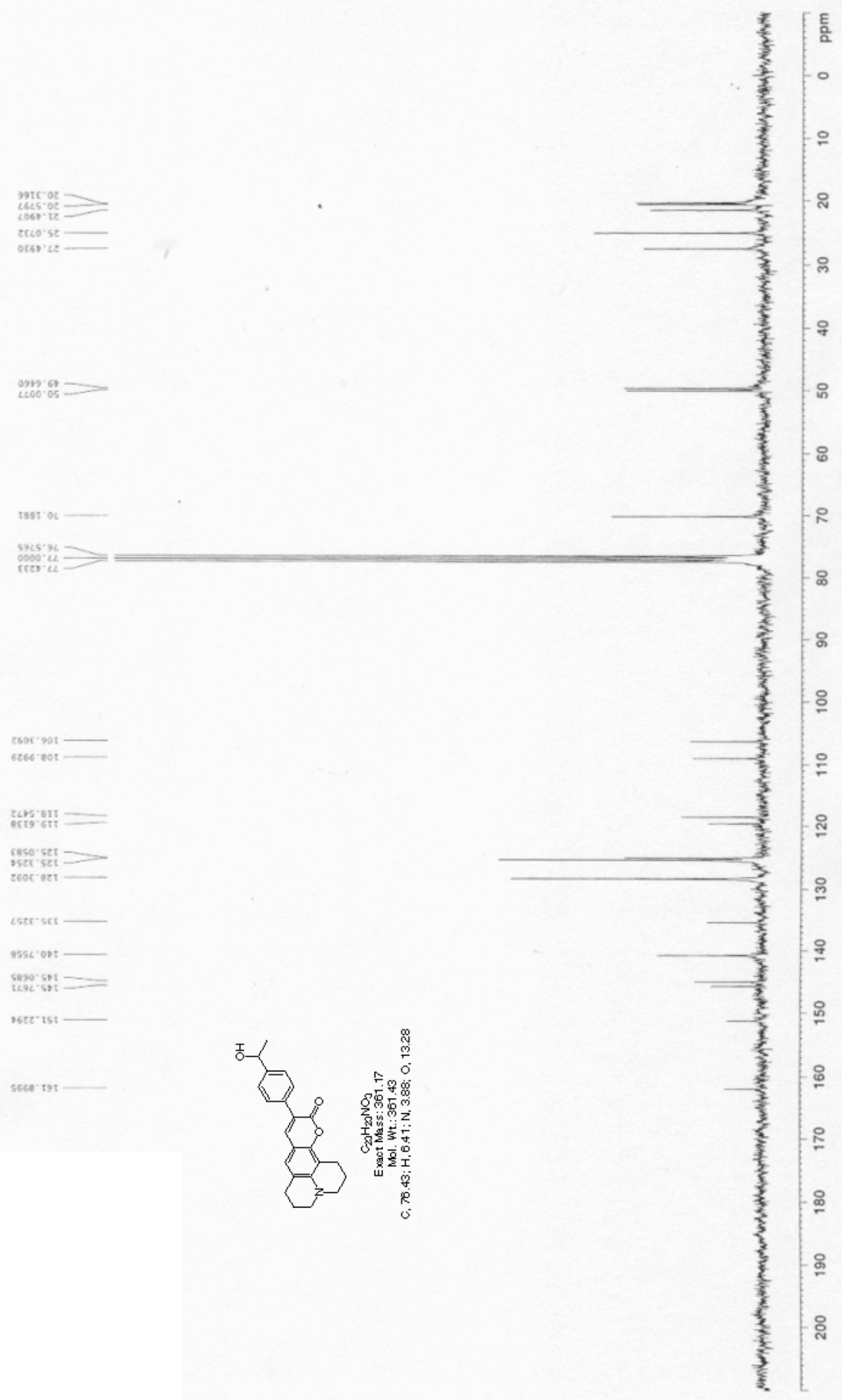

S42 
$\operatorname{coto}^{2} 0-2$

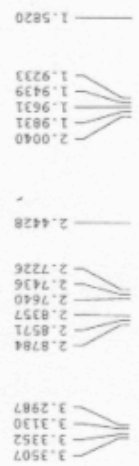

25te'
2Ste
Lose'

80ะR.9-

$6 \operatorname{tg} C^{*} \mathrm{C}$

$569 c^{\circ} \cdot 2$

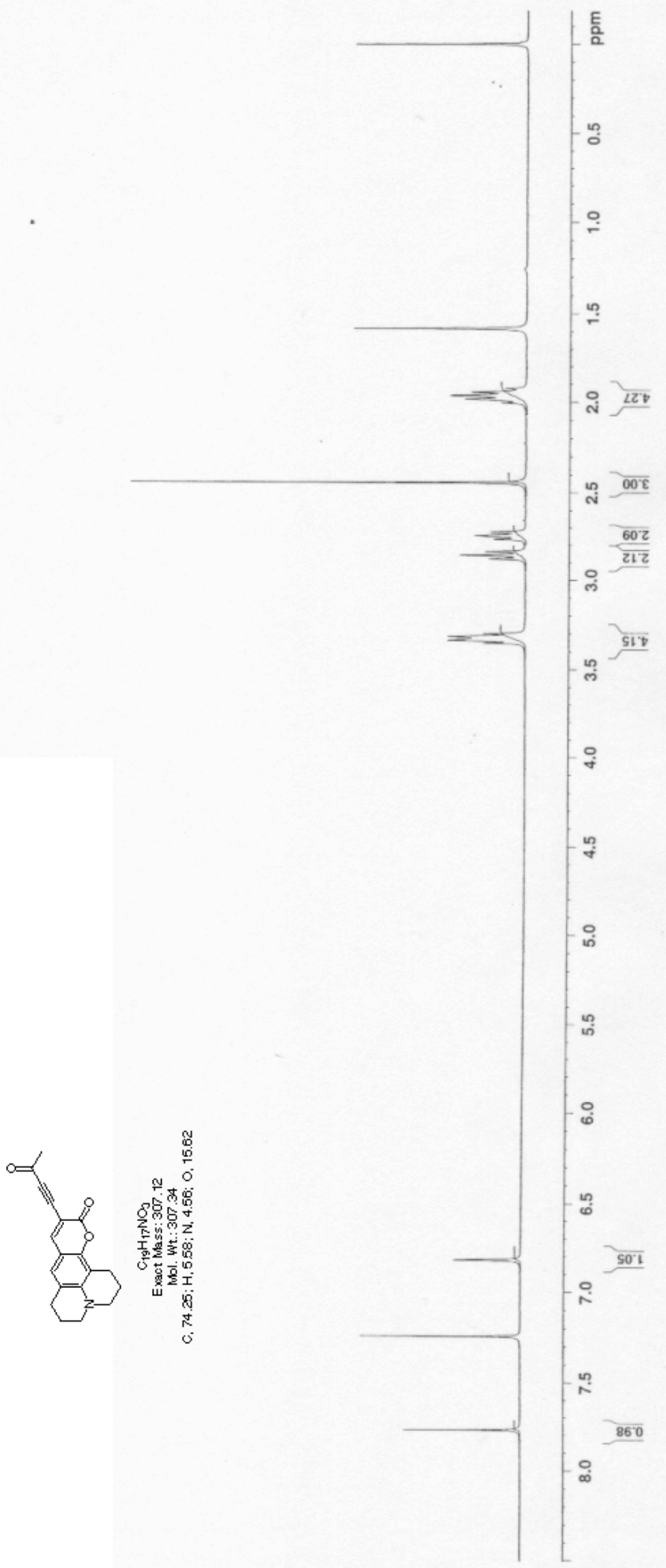

S43 

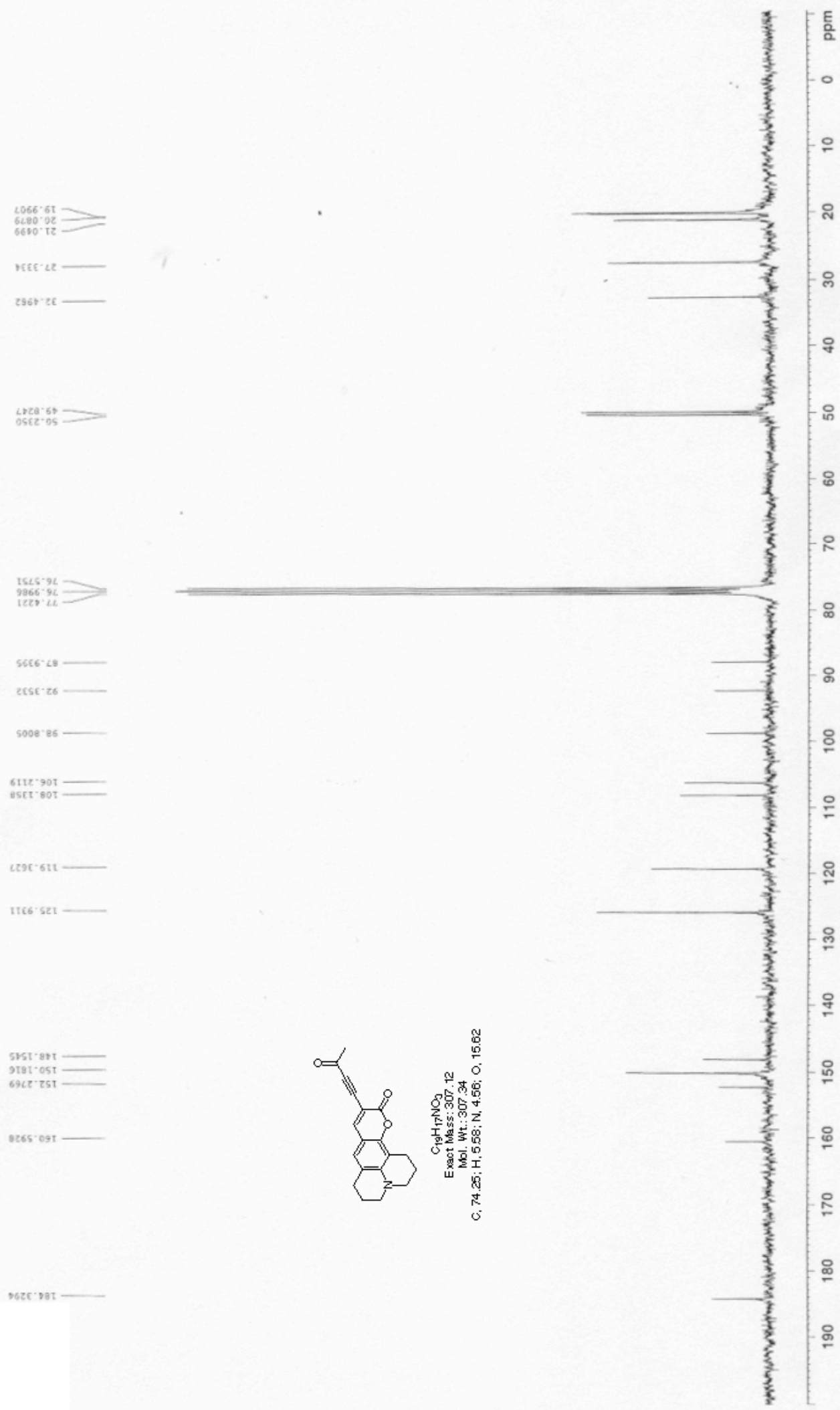


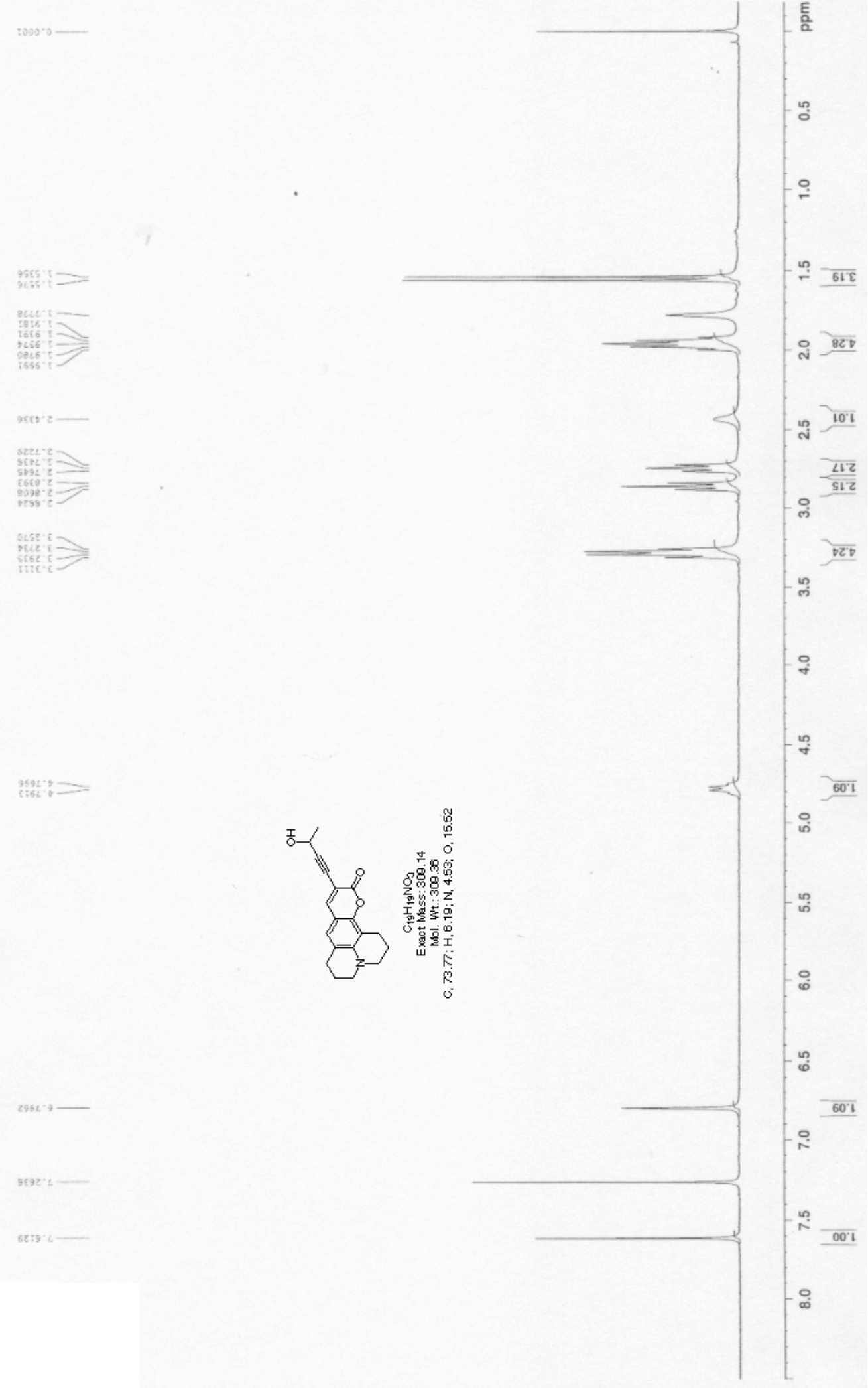




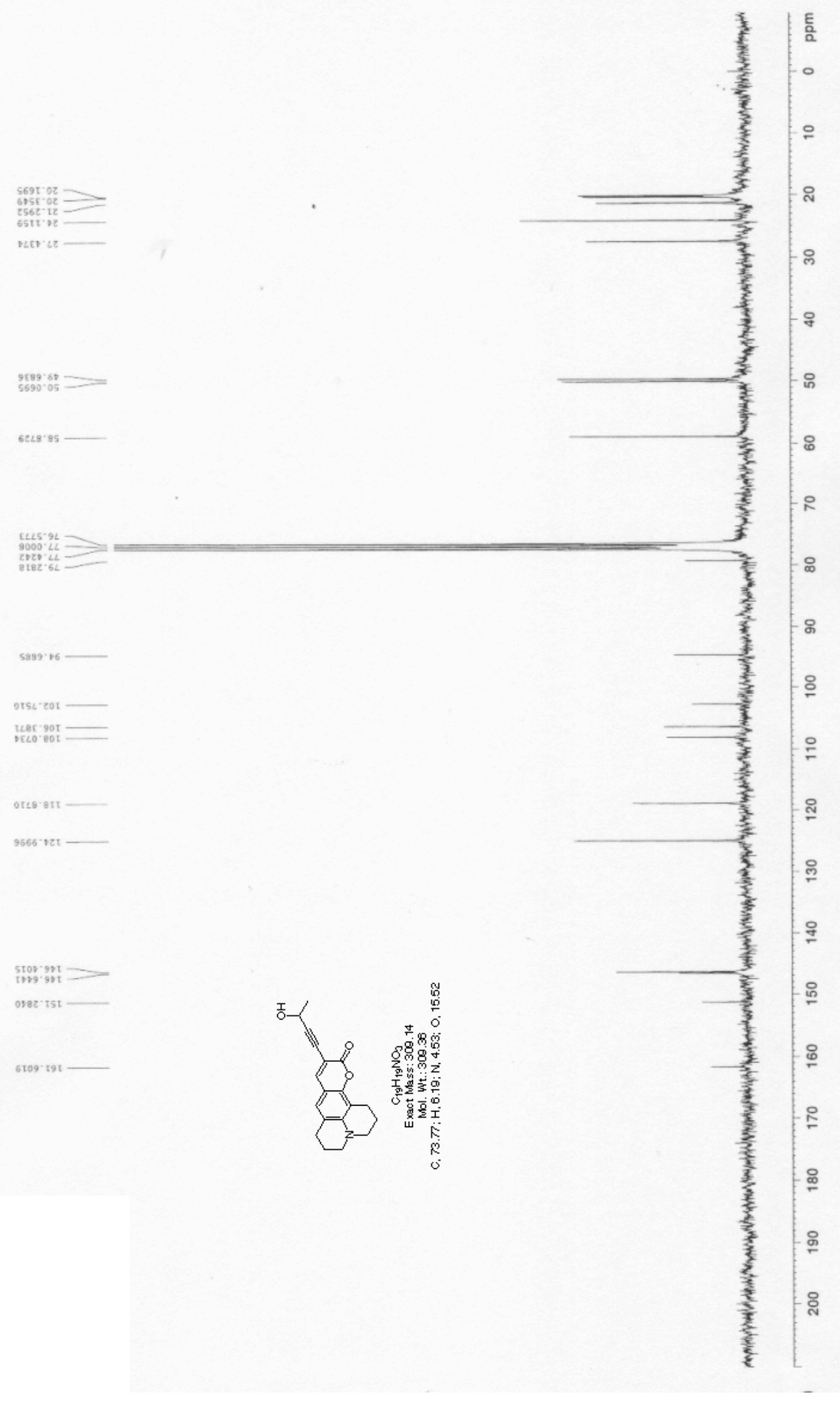




\section{References}

1. Heinrich, G.; Schoof, S.; Gusten, H. J. Photochem. 1974/75, 3, 312-320.

2. Reynolds, G. A.; Drexhage, K. H. Opt. Commun. 1975, 13, 222.

3. Jacobson, A.; Petric, A.; Hogenkamp, D.; Sinur, A.; Barrio, J. R. J. Am. Chem. Soc. 1996, 118, 5572-5579.

4. Hundertmark, T.; Littke, A. F.; Buchwald, S. L.; Fu, G. C. Org. Lett. 2000, 2, 17291731.

5. Balo, C.; Fernandez, F.; Garcia-Mera, X.; Lopez, C. Org. Prep. Proced. Int. 2000, 32, 367-372.

6. Coleman, R. S.; Madaras, M. L. J. Org. Chem. 1998, 63, 5700-5703.

7. Wierzchowski, J.; Dafeldecker, W. P.; Holmquist, B.; Vallee, B. L. Anal. Biochem. 1989, $178,57-62$

8. http://www.erithacus.com/grafit

9. Wilkinson, G. N. Biochem. J. 1961, 80, 324-332

10. Yee, D. J.; Balsanek, V.; Sames, D. unpublished results. 